\begin{tabular}{|l|l|}
\hline $\begin{array}{l}\text { 2. To: (Receiving Organization) } \\
\text { LMHC Characterization Engineering }\end{array}$ & $\begin{array}{l}\text { 3. From: (Originating Organization) } \\
\text { Characterization Engineering }\end{array}$ \\
\hline 5. Proj/Prog./Dept/Div.: & 6. Design Authority/Design Agent/Cog. Engr.: \\
Characterization Project & GP Janicek/BL Coverdell/RN Dale \\
\hline 8. Origintor Remark:
\end{tabular}

8. Originator Remarks:

Supporting document submitted for review and approval prior to release.

11. Receiver Remarks:

11A. Design Baseline Document? Yes No

This document represents 'independent Design Verification'

performed by analysis per hiF-IP-0842, Vol. iv, Section 4.24,

in support of design modification made against drawing/

$\mathrm{H}-2-85633$ by Rev. I and ECN 651132 .

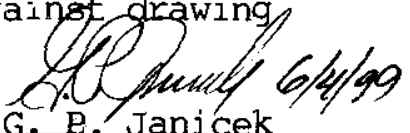

4. Related EDT No.:
N/A
7. Purchase Order No.:
N/A

9. Equip./Component No:

N/A

10. System/Bldg./Facility:

$200 \mathrm{G}$

12. Major Assm. Dwg. No.:

N/A

13. Permit/Permit Application No.:

N/A

14. Required Response Date:

ASAP

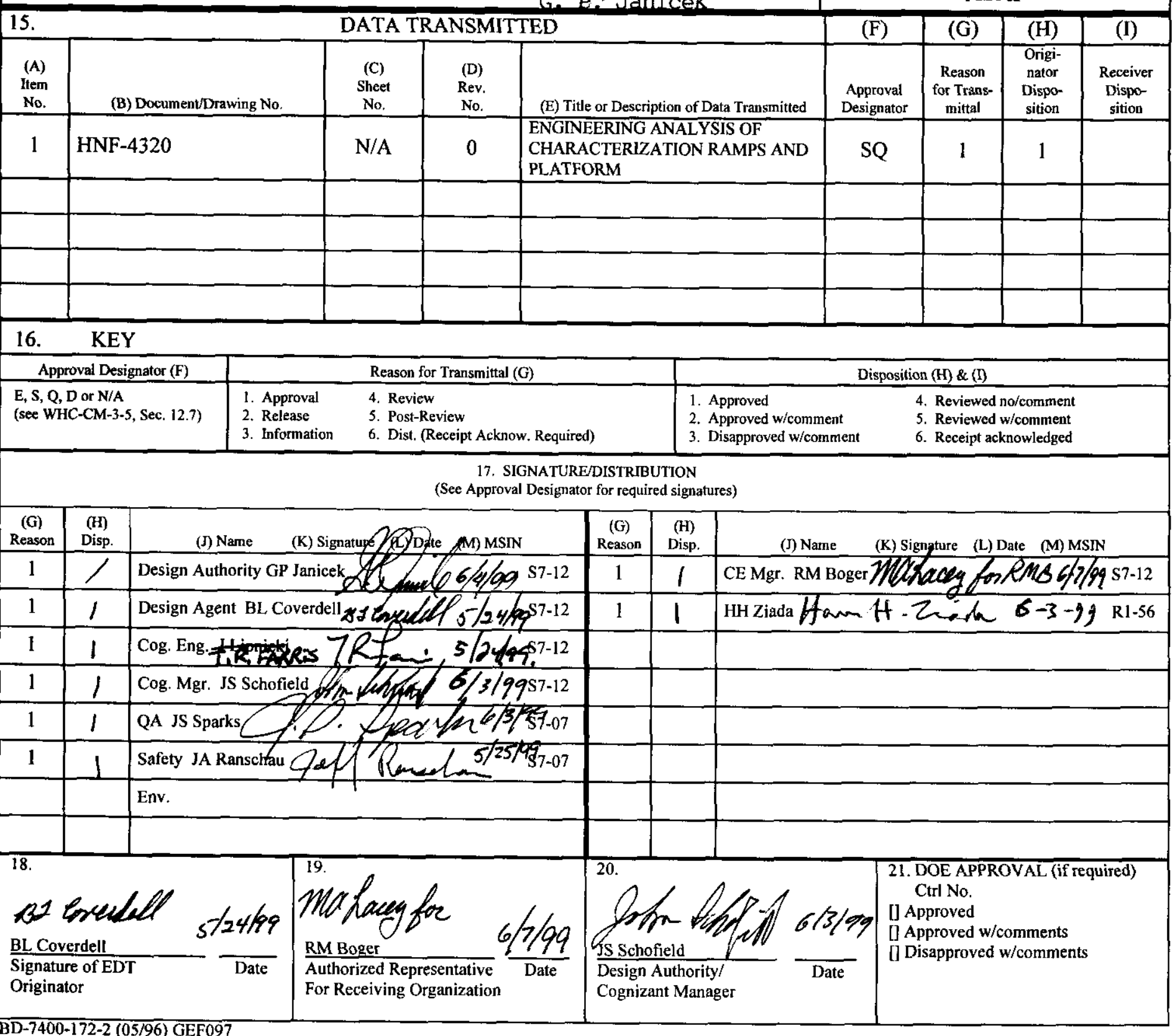




\title{
ENGINEERING ANALYSIS OF CHARACTERIZATION RAMPS AND PLATFORMS
}

\author{
R. M. Boger \\ Prepared by Lockheed Martin Hanford Company \\ 2400 Stevens \\ Richland, WA 99352 \\ U.S. Department of Energy Contract DE-AC06-96RL13200
}

EDT/ECN: 623355

Org Code: 74900

B\&R Code: EW3120074
UC: 2070

Charge Code: CACN: 102613 COA: EI00

Total Pages: 40
Key Words: Characterization Project, Core Sampling, Ramp, Platform

Abstract: The calculations in Appendix A and B determine the adequacy of the ramps and platforms to accomplish two tasks

1) Core sampling using the modifications imposed by the use of a FDNW foundation at PFP.

2) Core sampling within the $200 \mathrm{E}$ and $200 \mathrm{~W}$ Tank Farms without the imposed modifications.

The calculations in this document determined that the ramps and platforms are adequate for use with core sampling equipment when sampling either tank $241-\mathrm{Z}-361$ or within $200 \mathrm{E}$ or $200 \mathrm{~W}$ Tank Farms. When sampling tank 241-Z-361 the modifications made by ECN 651132 must be implemented. These modifications are the addition of diagonal cross bracing on both the lateral and longitudinal sides. Also, a $11 / 4$ in. tie rod must connect both bases of each longitudinal side.

TRADEMARK DISCLAIMER. Reference herein to any specific commercial product, process, or service by trade name, trademark, manufacturer, or otherwise, does not necessarily constitute or imply its endorsement, recommendation, or favoring by the United States Government or any agency thereof or its contractors or subcontractors.

Printed in the United States of America. To obtain copies of this document, contact: Document Control Services, P.O. Box 950, Mailstop H6-08, Richland WA 99352, Phone (509) 372-2420; Fax (509) 376-4989.
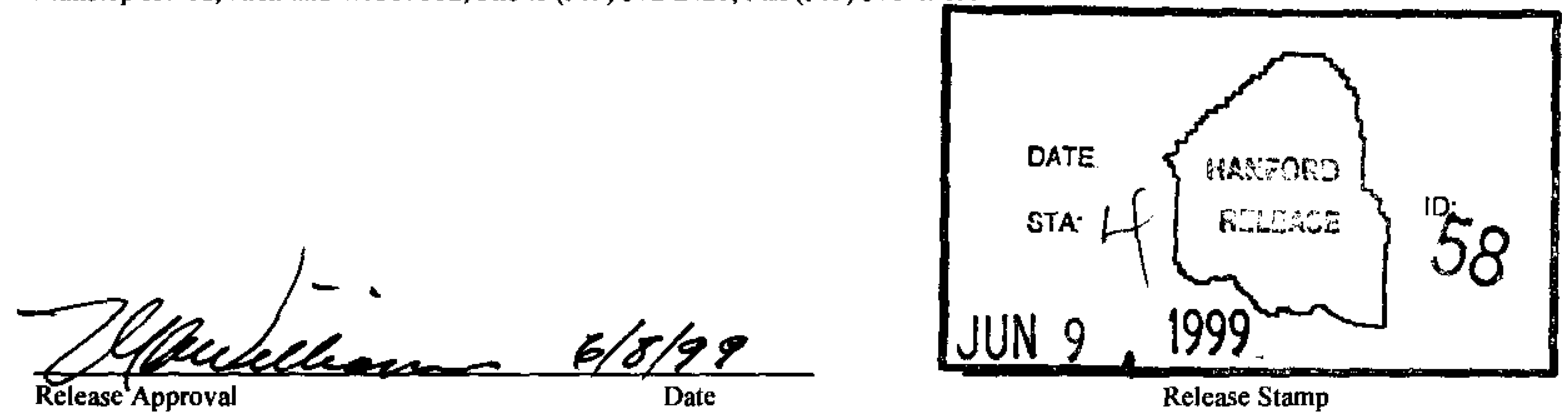

\section{Approved for Public Release}




\title{
ENGINEERING ANALYSIS OF CHARACTERIZATION RAMPS AND PLATFORMS
}

\author{
Prepared for Lockheed Martin Hanford Corporation \\ Characterization Engineering Group \\ By \\ B. L. Coverdell \\ COGEMA Engineering Corporation
}

May 1999 


\section{TABLE OF CONTENTS}

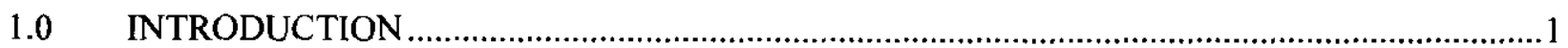

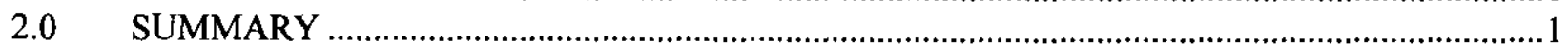

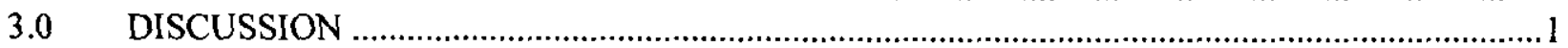

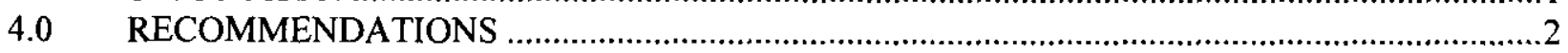

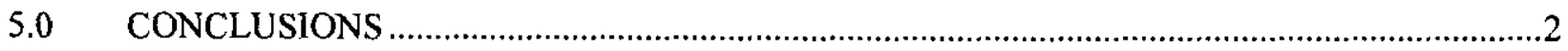

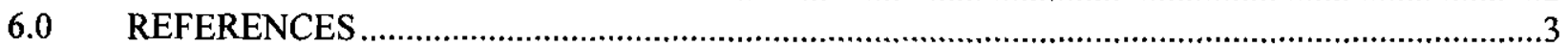

APPENDIX A: RAMP AND PLATFORM CALCULATIONS FOR 241-Z-361 ............................. A-1

APPENDIX B: TANK FARMS RAMP AND PLATFORM CALCULATIONS …..............................

APPENDIX C: TANK FARMS RAMP AND PLATFORM CALCULATIONS …................................ 
HNF-4320, Rev. 0

\section{$1.0 \quad$ INTRODUCTION}

The Plutonium Finishing Plant (PFP) sent much of its radioactive waste to tank 241-Z-361. The purpose of the tank was to allow solids contained in a radioactive waste solution to settle. In 1975, after many years of use, the tank was isolated and sealed.

Early in 1998, it was determined that the radioactive waste in tank 241-Z-361 should be characterized. The process of characterization of the tank contents requires that samples of the tank waste be taken. All core samples will be taken using existing core sample trucks (CSTs) specifically designed for core sampling. The weight of the CST to be used in the core sampling process is $26,000-1 b s$, however, the maximum weight of any of the four CSTs is $32,000-1 \mathrm{bs}$. The platforms have been loaded to a maximum weight of 32,000-lbs and this is documented in LMHC 1998. Also, measurements of the platform were taken to verify that the as-built drawings actually represent what is in the field. This was done to ensure that the calculations in Appendix A are correct. Due to the weight of the CST and the unknown condition of the tank roof, existing platforms will be used to span the tank. The platforms (WHC 1996a) will be anchored to a foundation designed by Fluor Daniel Northwest (FDNW 1999). During the initial phase of the foundation design it was determined that the foundation can not take any imposed moments. For this reason, modifications where required to the original platform design. These modifications are documented in Engineering Change Notice (ECN) 651132 (reference) which is written against the ramps and platform drawing (WHC, 1996a).

The calculations in Appendix A and B determine the adequacy of the ramps and platforms to accomplish two tasks

1) Core sampling using an alternate configuration imposed by the use of a FDNW foundation at PFP.

2) Core sampling within the $200 \mathrm{E}$ and $200 \mathrm{~W}$ Tank Farms using either configuration.

\subsection{SUMMARY}

The calculations in Appendices A and B determined that the ramps and platforms are adequate for use with core sampling equipment when sampling either tank $241-Z-361$ or within $200 \mathrm{E}$ or $200 \mathrm{~W}$ Tank Farms. When sampling tank 241-Z-361 the modifications made by ECN 651132 must be implemented. These modifications are the addition of diagonal cross bracing on both the lateral and longitudinal sides. In addition, a 1-1/4 in. tie rod must connect both bases of each longitudinal side. The platform is considered performance category 2 (PC 2) per Engineering Design and Evaluation, HNF-PRO-097 (FDH, 1997).

\subsection{DISCUSSION}

The analyses in Appendices A and B determined that the platform will support 35,000 lbs. The loads considered were;

- $\quad$ Core sample truck

- 10 people at $200 \mathrm{lbs}$. each

$32,000 \mathrm{lb}$,

$2,000 \mathrm{lbs}$,

- $\quad$ and miscellaneous weight $1,000 \mathrm{lbs}$.

The maximum wind loading on the core sample truck was determined to be $5400 \mathrm{lbs}$. in the lateral direction. Longitudinal loading due to a core sample truck stopping was also considered (also $5400 \mathrm{lb}$.). Seismic loading of the ramps and platforms is not considered in this analysis for the following reasons:

- When used for sampling of tank 241-Z-361 the Justification for Continued Operation for Tank 241-Z-361 (BWHC 1999) considers the ramps and platforms to be a temporary structure.

- When used to sample from tanks within Tank Farms, it has been determined that even if a core 
sample truck were to fall from a ramp it would not puncture or collapse a tank. This analysis is documented in the Structural Evaluation for the Core Sample Trucks RMCS Operations 200 Area (WHC 1996b).

The worst case loading of the platform was determined to be when the rear axle of a core sample truck is parked mid-span of the platform. Centering of a core sample truck on the platform was considered, however, the forces and moments due to this loading were found to be less than the configuration described previously.

Structural analysis of the platforms when used with the FDNW foundation required two load cases to be considered:

- The first load case was the load of the core sample truck plus the horizontal load due to the truck stopping plus the load due to humans plus miscellaneous equipment loading plus a $25 \mathrm{mph}$ wind loading.

- The second load case was the load of the core sample truck plus an $85 \mathrm{mph}$ wind loading, The second load case was determined to be the worst case, however, longitudinal loading due to a core sample truck stopping was also considered when applicable.

It should be noted that the loading due to uplift of the drill string was neglected in this analysis. Usually the weight of the drill string is very small, however, the drill string can get stuck in the waste. In this case the maximum uplift is limited by LMHC $1999 \mathrm{~b}$ to $2,000 \mathrm{lb}$. This force is less than the resulting down force from an $85 \mathrm{mph}$ wind $(3312 \mathrm{lb}$.) Combining the both of these load cases is not realistic since all work stops in Tank Farms at any wind speed over $25 \mathrm{mph}$.

\subsection{RECOMMENDATIONS}

The core sample truck platform is to be used in two different configurations; the first is on a foundation that requires special loading considerations and the second is when used within $200 \mathrm{E}$ and $200 \mathrm{~W}$ Tank Farms. When the platform is used on the foundation provided by FDNW then the modifications outlined by ECN 651132 MUST be implemented. The modifications prevent the transfer of moments from lateral and longitudinal loading to the foundation. Finally, when used in either configuration the $35,000 \mathrm{lb}$. load limit on the platform must not be exceeded.

\subsection{CONCLUSIONS}

Below is a list of conclusions based on use of the ramps and platforms for core sampling tank farms and tank 241-Z-361 using the foundation provided by FDNW:

- When placed on the foundation detailed in FDNW 1999, the ramps and platforms are structurally adequate to support a $35,000 \mathrm{lb}$. load provided that the alternate configuration is used as outlined in ECN 651132.

- The ramps and platforms do not need to be modified for any loads under $10,000 \mathrm{lb}$. provided that the load does not apply any significant lateral or longitudinal loading.

- When the ramps and platforms are used in either the 200E or 200W Tank Farms, the maximum load is also $35,000 \mathrm{lb}$, however, either configuration of the platform can be used. 


\subsection{REFERENCES}

BWHC, 1999, Justification for Continued Operations for Tank 241-Z-361, HNF-2024 Rev. 2, B\&W Hanford Company, Richland, Washington.

FDH, 1997, Engineering Design and Evaluation, HNF-PRO-097, Fluor Daniel Hanford, Inc., Richland, Washington.

FDNW, 1999, Civil Truck Ramp Platform Foundation Details, H-2-829739 Sheet 1-4, Fluor Daniel Northwest, Richland, Washington.

LMHC, 1998, Craft/Resource Usage Log and Maintenance Record (J-5), ES-98-00200, Lockheed Martin Hanford Corporation, Richland, Washington.

LMHC, 1999a, Engineering Change Notice, 651132, Lockheed Martin Hanford Corp., Richland, Washington.

LMHC, 1999b. Core Sampling with Trucks $3 \& 4$ (Rotary Bit), TO-080-518, Revision D-2, Lockheed Martin Hanford Corp., Richland, Washington.

WHC, 1996a, Structural Truck Ramp Platform Plan and Sections, H-2-85633 Sheet 1 Revision 0, Westinghouse Hanford Company.

WHC, 1996b, Structural Evaluation for the Core Sample Trucks RMCS Operations 200 Area, WHC-SD-WM-DA-215, Rev. 0, Westinghouse Hanford Company. 
HNF-4320

Rev. 0

APPENDIX A: Ramp and Platform Calculations for 241-Z-361

Page A-1 
HNF-4320

Rev. 0

迎, COGEMA

Client: Characterization Equipment Subject: Analysis of Core Sampling Platform

\section{DESIGN ANALYSIS}

Calc. No. BLC-Z361-R3

Revision

Page No.

$\frac{\frac{B L C-2361-R 3}{0}}{10 f 26}$

WO/Job No.

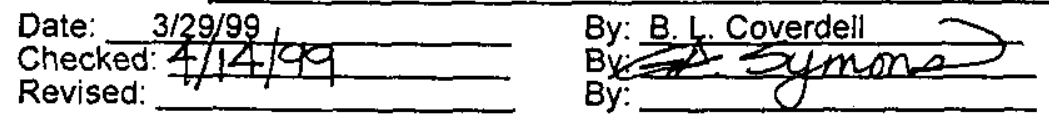

1.0 OBJECTIVE These calculations determine the structural adequacy of the core sampling platform for use in sampie tank 241-Z-361. The platform is considered performance category $2(P C 2)$ per Engineering Design and Evaluation, HNF-PRO-097. The platform supports a core sample truck weighing $32,000 \mathrm{lb}$, ten people each weighing $200 \mathrm{lb}$ and a $1000 \mathrm{lb}$ of miscellaneous equipment for a total weight of $35000 \mathrm{lb}$. An $85 \mathrm{mph}$ wind loading is also considered, however, this is not combined with the live loading due to personnel. Also, the live load due to stopping of the core sample truck shall be considered. Seismic loading is not considered a credible design load since this is a temporary structure. The platform working stresses will be calculated and compared to the allowable working stresses in American institute of Steel Construction, AISC 1989.

\subsection{DESIGN INPUTS}

2.1 Drawing: $\mathrm{H}-2-85633$

\subsection{ASSUMPTIONS}

3.1 Seismic loading is not considered to be a credible scenario since the platform is a temporary structure.

3.2 The center of pressure and the center of gravity are coincident.

3.3 The uplift due to $85 \mathrm{mph}$ wind will be neglected. This is conservative for two reasons: overturning of the core sample truck has already been analyzed and determined not be of concern (WHC 1995) and the uplift force would reduce the total load on the platform.

3.4 Given 3.2 and that the $\mathrm{Cg}$ is nearly over the rear axle, all the overturning force due to wind loading will be applied to the rear axle.

3.5 The $2 \mathrm{mph}$ velocity of core sample truck is based on operational experience.

3.6 For analysis purposes, the worst case scenario of the core sample truck on the platform is with the rear axle of the truck directly over the center of the platform. This load case requires that two platforms be used since the front axle extend onto it due to the length of the truck.

4.0 METHODS OF ANALYSIS (Hand calculations completed in Mathcad ver. 8.0)

\subsection{REFERENCES}

5.1 AlSC, 1989, Manual of Steel Construction, $9^{\text {th }}$ Edition, American Institute of Steel Construction, Chicago, Illinois.

5.2 ASCE, 1996, Minimum Design Loads for Buildings and Other Structures, ANSI/ASCE 7-95, American Society of Civil Engineers, Reston, Virginia.

5.3 Blodgett, OW, 1991, Design of Welded Structures, Fourteenth Printing. The James F. Lincoln Arc Welding Foundation, Cleveland, Ohio.

5.4 Coverdell, 1999. Design Loads and Center of Gravity For Core Sample Truck \#1, LMHC-9951531, Lockheed Martin Hanford Corp., Richland, Washington.

5.5 FDH, 1997, Engineering and Design and Evaluation, HNF-PRO-097, Fluor Daniel Hanford, Inc., Richland, Washington.

5.6 WHC, 1995, Structural Evaluation for Core Sampling Trucks, RMCS Operations, 200 Area, WHC-SD-WM-DA-215, Westinghouse Hanford Company. 
HNF-4320

Rev. 0

6.0 FINDINGS AND CONCLUSIONS The calculations in this below determined that the core sampling platform is adequate to support the $32000 \mathrm{lb}$ core sample truck pius the weight of 10 people plus $1000 \mathrm{lb}$ due to cask and cask stand for a total of $(35000 \mathrm{lb})$. NOTE: the casks and cask stand are positioned between two platforms side-by-side.

7.0 Load Cases Following are the load cases to be considered in these calculations.

NOTE: 1) Dead weight of the beams was considered and found to be negligible.

2) Core sampling operations cease in sustained winds in excess of $25 \mathrm{mph}$.

7.1 LL (Core Sample Truck) + LL (Core Sample Truck Stopping) + LL (Cask) + LL (Humans) + Wind (25 mph).

7.2 LL (Core Sample Truck) + LL (Cask) + Wind (85 mph).

\subsection{CALCULATIONS}

8.1 Live Loads and core sample truck $\mathrm{Cg}$ location.

$P_{\text {truck }}:=32000 \cdot \mathrm{lb} \quad$ Live load due to core sample truck, Coverdell, 1999.

$P_{\text {human }}:=2000 \cdot \mathrm{lb} \quad$ Live load due to humans, Coverdell, 1999.

$P_{\text {cask }}:=1000 \cdot 1 \mathrm{~b}$

Live load due to casks and casks stand. NOTE: In service, this equipment will not be placed directly on a single platform but will be supported between two platforms.

$P_{\text {front }}:=11000 \cdot 1 b$

Weight of core sample truck front axle as record by the state of Washington.

$P_{\text {rear }}:=21000 \cdot 1 \mathrm{~b}$

Weight of core sample truck rear axle as recorded by the state of Washington.

$\mathrm{Cg}_{\mathrm{x}}:=156 \cdot$ in

Horizontal distance to CG of sample truck. Measured from center of front axle,

$\mathrm{Cg}_{\mathrm{y}}:=64.3 \cdot \mathrm{in}$ WHC 1995.

Vertical distance from top of platform to CG of sample truck, Coverdell 1999.

8.2 Determine the maximum wind force on the core sample truck given that the truck is performance category 2 (PC2) and for a $25 \mathrm{mph}$ wind.

$\mathrm{X}_{\mathrm{z}}:=.85$

$\mathrm{K}_{\mathrm{zt}}:=1$

$\mathrm{I}:=1.07$

$\mathrm{V}_{85}:=85$

$q_{z_{-} 85}:=.00256 \cdot K_{z} \cdot K_{z t} \cdot I \cdot V_{85}{ }^{2} \cdot \frac{\mathrm{lb}}{\mathrm{ft}^{2}}$

$\mathrm{G}:=.85$

$\mathrm{C}_{\mathrm{f}}:=1.5$

$A_{\mathrm{f}}:=36128 \cdot \mathrm{in}^{2}$

$P_{w_{-} 85}:=q_{z_{-} 85} \cdot G \cdot C_{f} A_{f}$

$\mathrm{V}_{25}:=25$

$\mathrm{q}_{\mathrm{z}_{-} 25}:=.00256 \cdot \mathrm{K}_{\mathrm{z}} \cdot \mathrm{K}_{\mathrm{Zt}} \cdot \mathrm{I} \cdot \mathrm{V}_{25}{ }^{2} \cdot \frac{\mathrm{lb}}{\mathrm{ft}^{2}}$

$P_{w_{-} 25}:=q_{z_{-} 25} \cdot G \cdot C_{f} A_{f}$
Exposure category C, table 6-3 of ASCE 1996.

Per paragraph 6.5.5 of ASCE 1996.

Importance factor (HNF-PRO-097, 1997).

Wind velocity per (HNF-PRO-097, 1997).

$q_{z_{-} 85}=16.822 \cdot \frac{\mathrm{lb}}{\mathrm{ft}^{2}} \quad$ Velocity pressure.

Gust effect factors determined from paragraph 6.6.1 of ASCE 1996.

From Table 6-8 of ASCE 1996 given a height of $10 \mathrm{ft}$.

Surface area of truck from WHC 1995.

$\mathrm{P}_{\mathrm{w}_{-} 85}=5381 \mathrm{lb} \quad$ Wind force on core sample truck.

$25 \mathrm{mph}$ Wind velocity. This is the maximum wind velocity the operations will use the core sample truck in.

$\mathrm{q}_{z_{-} 25}=1.455 \cdot \frac{\mathrm{lb}}{\mathrm{ft}^{2}} \quad$ Velocity pressure.

$P_{W_{-} 25}=465 \mathrm{lb} \quad$ Wind force on core sample truck. 
HNF-4320

Rev. 0

8.3 Determine the force applied to the platform by a core sample truck stopping.

$\mathrm{V}_{1}:=2 \cdot \mathrm{mph}$

$\mathrm{V}_{2}:=0 \cdot \mathrm{mph}$

$\mathrm{m}:=35000 \cdot 1 \mathrm{~b}$

$t:=.6 \cdot \sec$
Maximum velocity of core sample truck based on operational experience.

Final velocity of core sample truck.

Mass of core sample truck in lbs mass.

Estimated time required to stop core sample truck based on operational experience.

Use Kinetic Energy Theory

$\mathrm{d}:=\frac{\mathrm{V}_{1}-\mathrm{V}_{2} \cdot \mathrm{t}}{2} \quad \mathrm{~d}=10.56$ in

Work done $=\mathrm{K}$. E.

$P_{\text {stop }} \cdot d:=\frac{1}{2} \cdot m \cdot V_{1}^{2}$

$P_{\text {stop }}:=\frac{\frac{1}{2} \cdot \mathrm{m} \cdot \mathrm{V}_{1}{ }^{2}}{\mathrm{~d}}$
Distance required to stop core sample truck given an initial velocity of $2 \mathrm{mph}$.

8.4 Determine the increased reaction force on the rear axle due to a $85 \mathrm{mph}$ wind loading and a $25 \mathrm{mph}$ wind loading.

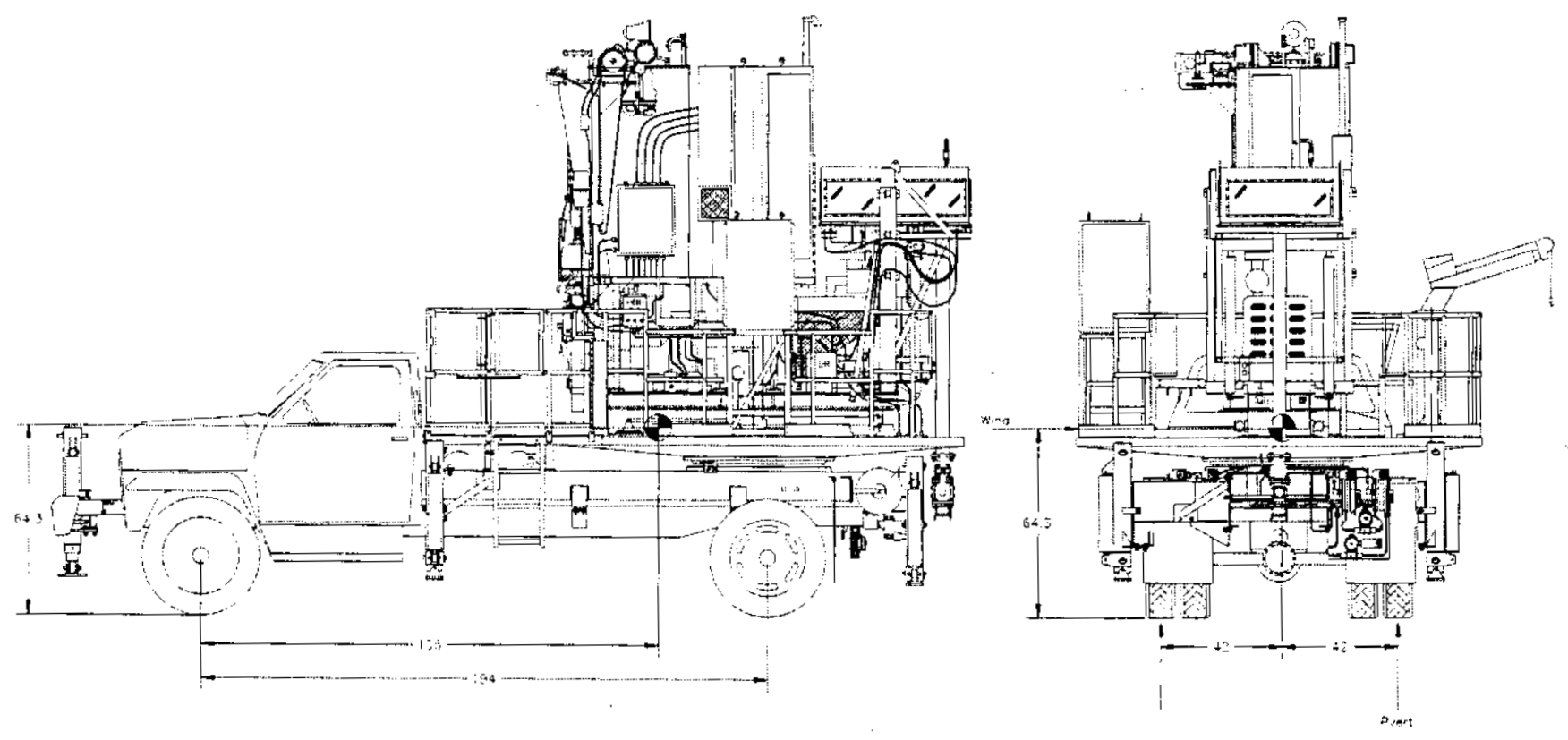

BEST AVAILABLE COPY 
HNF-4320

Rev. 0
$e_{1}:=84 \cdot$ in
Distance between tire center lines on rear axle.
$e_{2}:=194 \cdot$ in
Distance between centerlines of front and rear tires.
$r_{\text {rear85 }}:=\frac{\mathrm{Cg}_{x} \cdot P_{w_{-} 85}}{e_{2}}$
$r_{\text {rear85 }}=4327 \mathrm{lb}$
$85 \mathrm{mph}$ wind force on rear axle, WHC 1995.
$\mathrm{r}_{\text {rear25 }}:=\frac{\mathrm{Cg}_{\mathrm{x}} \cdot \mathrm{P}_{\mathrm{w}_{2} 25}}{\mathrm{e}_{2}}$
$r_{\text {rear25 }}=374 \mathrm{lb}$
$25 \mathrm{mph}$ wind force on rear axle, WHC 1995.
$r_{w_{-} 85}:=\frac{\mathrm{Cg}_{y} \cdot r_{\text {rear85 }}}{\mathrm{e}_{1}}$
$r_{w_{-} 85}=3312 \mathrm{lb}$
Additional force on one side of rear axle due to $85 \mathrm{mph}$ wind loading, WHC 1995.
$r_{w_{-} 25}:=\frac{\mathrm{Cg}_{y{ }^{r} \text { rear25 }}}{\mathrm{e}_{1}}$
$r_{w_{-} 25}=287 \mathrm{lb}$
Additional force on one side of rear axle due to $25 \mathrm{mph}$ wind loading. 46" obtained from 84 " rear axle tire width / 2 , WHC 1995.

8.5 The allowable stresses for A36 and A500 Grade B material per AISC 1989 are shown below.
$\sigma_{y_{-} a 36}:=36000 \cdot \frac{\mathrm{lb}}{\mathrm{in}^{2}}$
Yield stress of A36 material.
$\sigma_{\mathrm{t}_{-} \mathrm{a} 36}:=0.6 \cdot \sigma_{\mathrm{y}_{-}} \mathrm{a} 36$
$\sigma_{t \_a 36}=21600 \cdot \frac{\mathrm{lb}}{\mathrm{in}^{2}}$
The allowable tensile stress.
$\sigma_{b_{-} a 36}:=0.66 \cdot \sigma_{y \_a 36}$
$\sigma_{\text {b_a36 }}=23760 \cdot \frac{\mathrm{lb}}{\mathrm{in}^{2}}$
The allowable strong bending stress.
$\tau_{\mathrm{v} \_\mathrm{a} 36}:=0.4 \cdot \sigma_{\mathrm{y}} \mathrm{a} 36$
$\tau_{v_{-} \text {a36 }}=14400 \cdot \frac{\mathrm{lb}}{\mathrm{in}^{2}}$
The allowable shear stress.
$\sigma_{y_{-}} 5500:=46000 \cdot \frac{\mathrm{lb}}{\mathrm{in}^{2}}$
Yield stress of A500 Grade B material.
$\sigma_{t_{-} a 500}:=0.6 \cdot \sigma_{y_{-} a 500}$
$\sigma_{t_{-} a 500}=27600 \cdot \frac{\mathrm{lb}}{\mathrm{in}^{2}}$
The allowable tensile stress.
$\sigma_{\text {b_a } 500}:=0.66 \cdot \sigma_{y_{-}} a 500$
$\sigma_{\text {b_a } 500}=30360 \cdot \frac{\mathrm{lb}}{\mathrm{in}^{2}}$
The allowable strong bending stress.
$\tau_{v_{-} a 500}:=0.4 \cdot \sigma_{y_{-}} a 500$

$$
\tau_{v_{-}} \text {a500 }=18400 \cdot \frac{\mathrm{lb}}{\mathrm{in}^{2}}
$$
The allowable shear stress.

8.6 Calculate the maximum horizontal and vertical loadings for load cases one and two.

Load Case One

$P_{\text {vertl }}:=\frac{P_{\text {rear }}}{2}+\frac{P_{\text {cask }}}{2}+\frac{P_{\text {human }}}{4}+r_{W_{-} 25} \quad P_{\text {vert } 1}=11787 \mathrm{lb}$

Vertical Loading: $1 / 2$ rear axle load $+1 / 2$ the cask load + human load evenly distributed over the four legs of a platform $+25 \mathrm{mph}$ wind load.

$\mathrm{P}_{\text {horzl }}:=\mathrm{P}_{\text {stop }}$

$P_{\text {horzl }}=5318 \mathrm{alb} \quad$ Horizontal Loading due to truck stopping.

$\mathrm{P}_{\mathrm{w}_{-} 25}=465.494 \mathrm{lb}$

The lateral loading due to a $25 \mathrm{mph}$ wind is negligible. 
HNF-4320

Rev. 0

Load Case Two

$P_{\text {vert2 }}:=\frac{P_{\text {rear }}}{2}+\frac{P_{\text {cask }}}{2}+r_{w_{-} 85} \quad P_{\text {vert2 }}=14312 \mathrm{lb} \quad \begin{aligned} & \text { Vertical Loading: } 1 / 2 \text { rear axle load }+1 / 2 \text { cask load } \\ & +85 \mathrm{mph} \text { wind load. }\end{aligned}$

$\mathrm{P}_{\text {horz2 }}:=\mathrm{P}_{\mathrm{w}_{-} 85} \quad \mathrm{P}_{\text {horz2 }}=5381 \mathrm{elb} \quad$ Horizontal Loading due to wind.

Note: Load case two is the governing load case and will be used for all analysis, however, the horizontal load due to stop of the core sample truck will be used when deemed applicable.

8.7 Determine the maximum stresses in the W8x18 using the loads calculated above. Consider the two W8x18s to be a simply supported beam. Use the formulas from AISC 1989, Page 2-298, Diagram 7 to determine the maximum bending stress and shear stress.

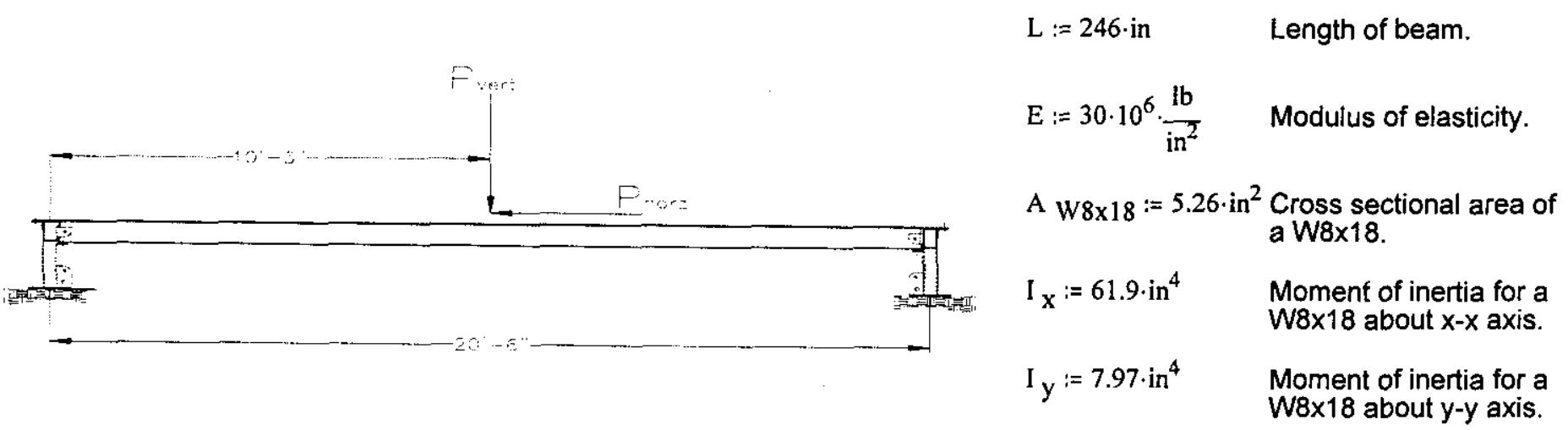

Determine the actual section modulus of the built-up section (W8x18s and $3 / 16$ in. diamond plate).

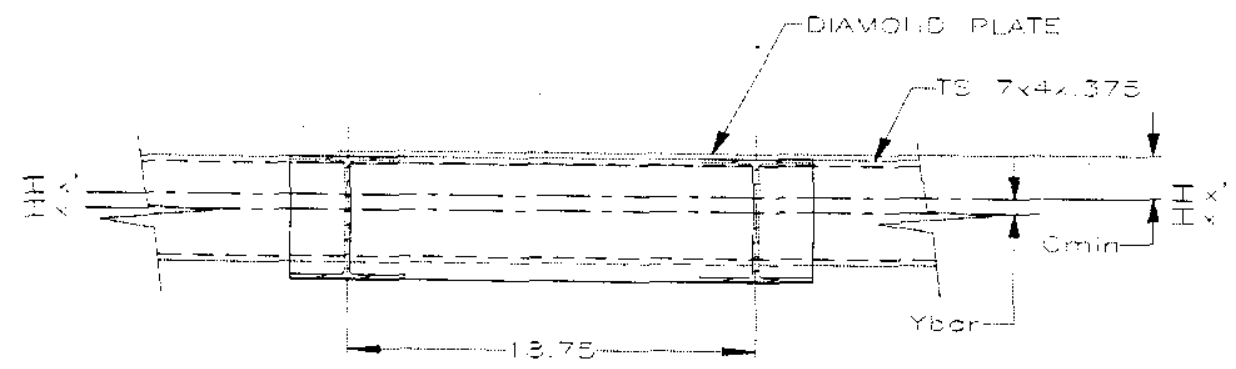

$I_{x \_p l}:=\frac{1}{12} \cdot 20 \cdot \mathrm{in} \cdot \frac{3}{16} \cdot \mathrm{in}^{3} \quad I_{x \_p l}=0.011 \cdot \operatorname{in}^{4}$

$A_{p l}:=\frac{3}{16} \cdot \mathrm{in} \cdot 20 \cdot$ in $\quad A_{\mathrm{pl}}=3.75 \cdot \mathrm{in}^{2} \quad$ Cross sectional area of the diamond plate.

$y_{\mathrm{pl}}:=4.07 \cdot \mathrm{in}+\frac{\frac{3}{16} \cdot \mathrm{in}}{2} \quad \mathrm{y}_{\mathrm{pl}}=4.164$ in

$\mathrm{y}_{\text {bar }}:=\frac{\mathrm{y}_{\text {pl }} \cdot \mathrm{A}_{\mathrm{pl}}}{2 \cdot \mathrm{A}_{\mathrm{W}} \mathrm{X} \times 18+\mathrm{A}_{\mathrm{pl}}} \quad \mathrm{y}_{\text {bar }}=1.094 \cdot$ in

Distance from the horizontal centerline of the W8x18s to the centroid of the diamond plate.

Distance from horizontal centertine of the W8x18s to the neutral axis. 
HNF-4320

Rev. 0

$$
\begin{aligned}
& c_{\min }:=4.07 \cdot \text { in }+\frac{3}{16} \cdot \text { in }-y_{\text {bar }} \quad c_{\min }=3.163 \text { in } \\
& \text { Minimum distance from neutral axis to outer most point of } \\
& \text { built-up beam. } \\
& c_{\max }:=4.07 \cdot \text { in }+y_{\text {bar }} \quad c_{\max }=5.164 \text { in } \\
& d_{p l}:=c_{\min }-\frac{\frac{3}{16} \cdot{ }^{\text {in }}}{2} \\
& \mathrm{~d}_{\mathrm{pl}}=3.07 \text {.in } \\
& I_{p l}:=I_{x \_p l}+A_{p l} \cdot d_{p l}^{2} \quad I_{p l}=35.344 \cdot \mathrm{in}^{4} \\
& { }^{1} x^{\prime}:=2 \cdot{ }^{1} x+1 \text { pl } \quad I_{x^{\prime}}=159.144 \cdot \mathrm{in}^{4} \\
& \text { Maximum distance from neutral axis to outer most point of } \\
& \text { built-up beam. } \\
& \text { Distance from neutral axis to centroid of plate. } \\
& \text { Moment of inertia of the diamond plate (parallel axis } \\
& \text { theorem. } \\
& d:=\frac{18.75 \cdot \text { in }}{2} \\
& \text { Distance from centerline to outer most fiber of W } 8 \times 18 \text { s. } \\
& I_{y^{\prime}}:=2 \cdot\left(I_{y}+A \text { W } 8 \times 18 \cdot d^{2}\right) \\
& \mathrm{I}^{\prime}=940.549 \cdot \mathrm{in}^{4} \\
& \text { ly' does not include diamond plate. } \\
& S_{X^{\prime}}:=\frac{\mathfrak{l}_{x^{\prime}}}{c_{\max }} \\
& \mathrm{S}_{\mathrm{X}^{\prime}}=30.817 \cdot \mathrm{in}^{3} \\
& S_{y^{\prime}}:=\frac{I y^{\prime}}{\frac{d+5.25 \cdot i n}{2}} \\
& S_{y^{\prime}}=128.622 \cdot \mathrm{in}^{3}
\end{aligned}
$$

Determine the maximum tensile stress on the W8x18s.

$$
\sigma_{\mathrm{t}}:=\frac{\mathrm{P}_{\text {horzl }}}{2 \cdot \mathrm{A} \text { W } 8 \times 18} \quad \sigma_{\mathrm{t}}=505.513 \circ \frac{\mathrm{lb}}{\mathrm{in}^{2}}
$$

Answer $:=$ if $\left(\sigma_{t}<\sigma_{t}\right.$ a36, "OK", "No Good" $) \quad$ Answer $=$ "OK" $\quad \begin{aligned} & \text { Beams are adequate per AISC 1989, Page } \\ & 5-40 \sigma .\end{aligned}$

Determine the maximum bending stresses on the W8x18s.

$$
\begin{aligned}
& \mathrm{Mx}_{\max }:=\frac{\mathrm{P}_{\text {vert } 2} \cdot \mathrm{L}}{4} \quad \mathrm{Mx} \text { max }=880205 \mathrm{ein} \cdot \mathrm{lb} \quad \text { Maximum moment in the W8x18 built-up section per } \\
& \sigma_{b x}:=\frac{M x_{\max }}{\mathrm{S}_{\mathrm{x}^{\prime}}} \quad \sigma_{\mathrm{bx}}=28562 \cdot \frac{\mathrm{lb}}{\mathrm{in}^{2}} \quad \text { Maximum stress in the W8x18 built-up section. } \\
& \text { AISC 1989, Page 2-298, Diagram } 7 \text { (pinned ends). }
\end{aligned}
$$

$$
\begin{aligned}
& \text { Answer }=1{ }^{\prime}(0 \text { Beams are adequate per AISC 1989, Page } \\
& \begin{array}{ll}
P \text { horz2 } & \text { allowable stre } \\
& \text { Page } 5.30 .
\end{array}
\end{aligned}
$$
My $_{\max }:=\frac{\frac{2}{4} \cdot \mathrm{L}}{4} \quad$ My max $_{\text {max }}=165469$ in $\cdot \mathrm{lb} \quad \begin{aligned} & \text { Maximum moment in the w8x18 built-up section per } \\ & \text { AlSC 1989, Page 2-298, Diagram } 7 \text { (pinned ends). }\end{aligned}$

$\sigma_{\text {by }}:=\frac{\mathrm{My}_{\max }}{\mathrm{S}_{\mathrm{y}^{\prime}}} \quad \sigma_{\text {by }}=1286 \frac{\mathrm{lb}}{\mathrm{in}^{2}} \quad$ Maximum stress in the W8x18 built-up section.
Answer := if $\left(\sigma_{b y}<1.33 \cdot \sigma_{b}\right.$ a 36 , "OK", "No Good" $)$ Answer = "OK"
Beams are adequate per AISC 1989, Page 5-45, Equation F1-1. NOTE: use $1 / 3$ allowable stress increase per AISC 1989, Page 5-30.


AISC 1989 requires that the load cases that exclude wind be checked also. In these calculations this would be considered load case 1 even though a $25 \mathrm{mph}$ wind is considered. The lateral loading due to an $85 \mathrm{mph}$ wind is also considered (conservative).

$$
\begin{aligned}
& \mathrm{Mx}_{\max }:=\frac{\mathrm{P}_{\text {vert1 }} \cdot \mathrm{L}}{4} \quad \mathrm{Mx} \text { max }=724872 \text { in } \cdot \mathrm{lb} \quad \text { Maximum moment in the W8x18 built-up section per } \\
& \sigma_{b x}:=\frac{M x_{\max }}{S_{x^{\prime}}} \quad \sigma_{b x}=23522 \cdot \frac{\mathrm{lb}}{\mathrm{in}^{2}} \quad \text { Maximum stress in the W8x18 built-up section. }
\end{aligned}
$$$$
\text { Answer : }=\text { if }\left(\sigma_{b x}<\sigma_{b} \text { a36 },\right. \text { "OK", "No Good") Answer = "OK" Beams are adequate per AISC 1989, Page }
$$$$
\mathrm{My}_{\max }:=\frac{\mathrm{P}_{\text {hor22 }} \cdot \mathrm{L}}{4} \quad \mathrm{My}_{\max }=330938 \mathrm{in} \cdot \mathrm{lb} \quad \text { Maximum moment in the }_{\text {AISC }} 1989 \mathrm{x} 18 \text { built-up section per }
$$$$
\sigma_{\text {by }}:=\frac{\mathrm{My}_{\max }}{\mathrm{S}_{\mathrm{y}^{\prime}}} \quad \sigma_{\text {by }}=2573 \cdot \frac{\mathrm{lb}}{\mathrm{in}^{2}} \quad \text { Maximum stress in the W8x18 built-up section. }
$$$$
\text { Answer : }=\mathbf{i f}\left(\sigma_{\text {by }}<\sigma_{b_{-}} \text {a36 }, \text { "OK", "No Good" }\right) \quad \text { Answer = "OK" Beams are adequate per AISC 1989, Page }
$$

Determine the maximum shear stress on the W8x18s.
$A_{\text {web }}:=8.14 \cdot$ in $\cdot 0.23 \cdot$ in
$\mathrm{A}_{\mathrm{web}}=1.872 \cdot \mathrm{in}^{2}$
$\tau_{v_{-} \text {vert }}:=\frac{P_{\text {vert } 2}}{2 \cdot A_{\text {web }}}$
$\tau$ v_vert $=3822.315 \cdot \frac{\mathrm{lb}}{\mathrm{in}^{2}}$
Only the web will take shear in the vertical direction.
The maximum vertical shear stress. OK
Answer $:=$ if $\left(\tau v_{-}\right.$vert $<\tau v_{-}$a36, ${ }^{\text {"OK" }}$, "No Good" $) \quad$ Answer $=$ "OK"
Beams are adequate per AISC 1989, Page 5-45, Equation F1-1.
$\mathrm{A}_{\text {flan }}:=2 \cdot(5.25 \cdot \mathrm{in} \cdot 0.33 \cdot \mathrm{in})$
$\mathrm{A}_{\text {flan }}=3.465 \mathrm{oin}^{2}$
$\tau_{v_{-} \text {lat }}:=\frac{\frac{P_{\text {horz2 }}}{2}}{2 \cdot A_{\text {flan }}}$
$\tau_{v_{-} \text {lat }}=388.248 \cdot \frac{\mathrm{lb}}{\mathrm{in}^{2}}$
Only the flanges will carry the shear in the transversal direction.
The maximum lateral shear stress. OK
Answer : $=$ if $\tau^{\tau} v_{-}$lat $<\tau v_{-}$a36, "OK" , "No Good")
Answer $=$ "OK"
Beams are adequate per AISC 1989, Page

8.8 Determine the adequacy of the weld connecting the $3 / 16$ in. diamond plate to the W8x18s.
$\mathrm{V}:=\tau_{\text {I }}$-vert
$\mathrm{V}=3822.315 \cdot \frac{\mathrm{lb}}{\mathrm{in}^{2}}$
Vertical shear force.
$\mathrm{Q}:=\left(22 \cdot \mathrm{in} \cdot \frac{3}{16} \cdot \mathrm{in}\right) \frac{8.14 \cdot \mathrm{in}+\frac{3}{16} \cdot \mathrm{in}}{2} \quad \mathrm{Q}=17.175 \cdot \mathrm{in}^{3}$
First moment with respect to the neutral axis.
$I:=\frac{\frac{3}{16} \cdot \mathrm{in} \cdot(22 \cdot \mathrm{in})^{3}}{12}$
$I=166.375 \cdot \mathrm{in}^{4}$
Moment of inertia of $3 / 16$ in. plate.
$q:=\frac{Q \cdot V}{T}$
$q=6.819 \cdot 10^{5} \cdot \frac{\mathrm{lb}}{\mathrm{ft}^{3}}$
Horizontal shear flow. 
HNF-4320

Rev. 0

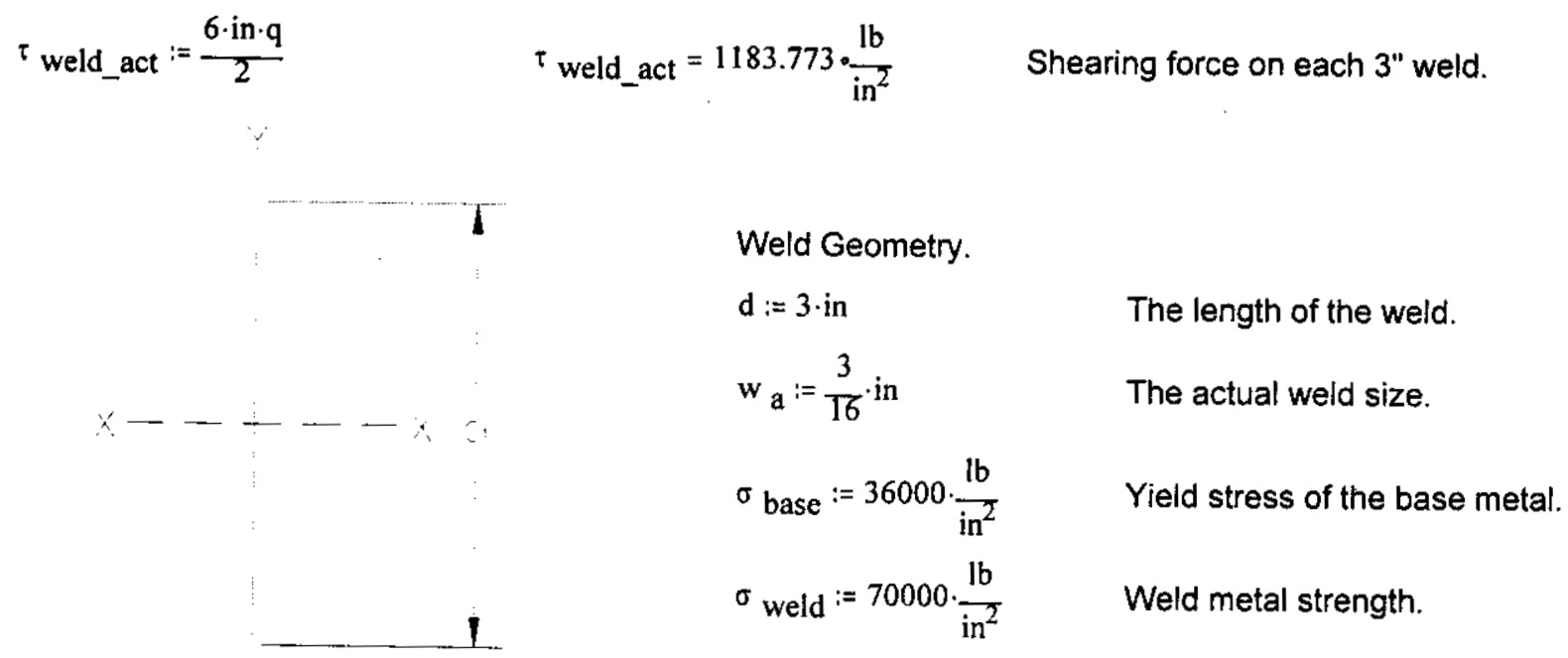

Allowable Shear:

$\tau_{\text {weld_all }}:=$ if $[0.4 \cdot \sigma$ base $\leq 0.707 \cdot 0.3 \cdot \sigma$ weld, $0.4 \cdot \sigma$ base, $0.707 \cdot(0.3) \cdot \sigma$ weld $] \quad \tau_{\text {weld_all }}=14400 \cdot \frac{\mathrm{lb}}{\mathrm{in}^{2}}$

The margin of safety:

MS : $=\frac{{ }^{\tau} \text { weld_all }}{{ }^{\tau} \text { weld_act }}-1 \quad$ MS $=11.164 \quad$ OK 8.9 Determine the adequacy of the TS $7 \times 4 \times 3 / 8$ beams, consider the beam to be simply supported. Use the formula from
AISC 1989 , Page $2-298$, Diagram 9 .

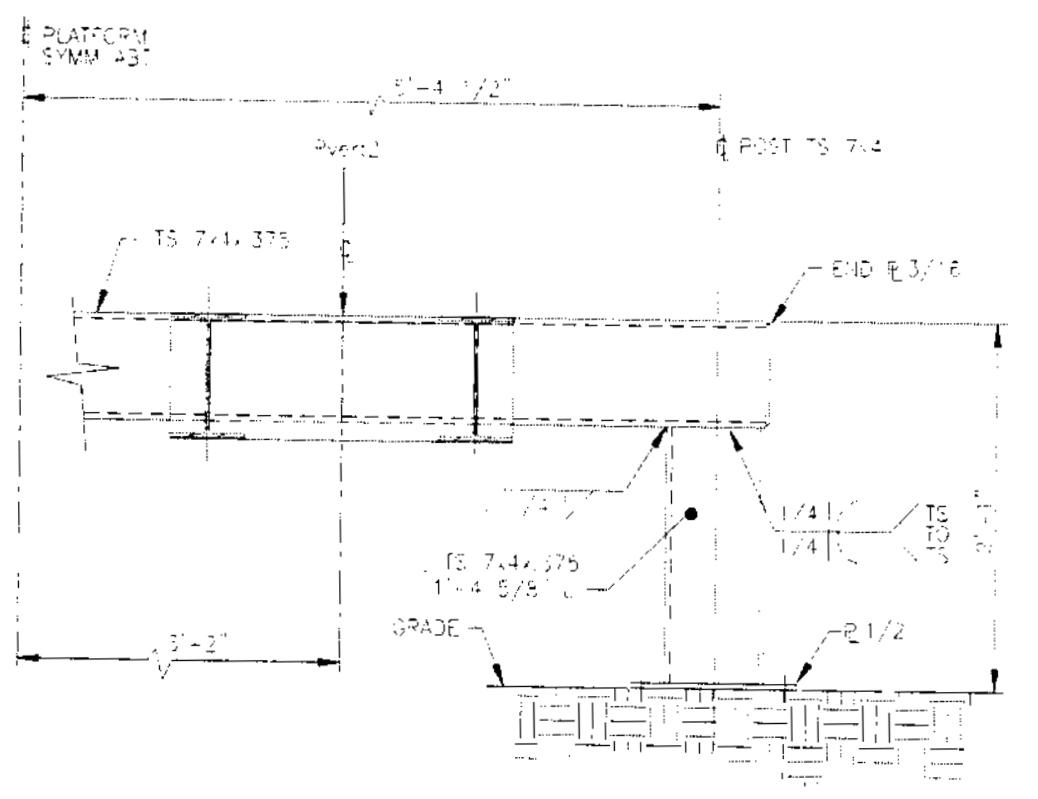
$a:=26.25 \cdot$ in Distance from centerline of W8 818 built-up section to centerline of TS $7 \times 4 \times 3 / 8$.

$A_{c}:=7.33 \cdot i^{2} \quad$ Cross sectional area TS $7 \times 4 \times 3 / 8$.

$\mathrm{S}_{X}:=12.6 \cdot \mathrm{in}^{3} \quad$ Strong axis section modulus for a TS $7 \times 4 \times 3 / 8$.

$\mathrm{S}_{\mathrm{y}}:=9.06 \cdot \mathrm{in}^{3} \quad$ Weak axis section modulus for a TS $7 \times 4 \times 3 / 8$. 
HNF-4320

Rev. 0

The actual moments and stresses in the TS $7 \times 4 \times 3 / 8$.

$\sigma_{\mathrm{t}}:=\frac{\frac{\mathrm{P}_{\text {horz2 }}}{2}}{\mathrm{~A}_{\mathrm{c}}} \quad \sigma_{\mathrm{t}}=367 \cdot \frac{\mathrm{lb}}{\mathrm{in}^{2}}$

Maximum tensile stress due to lateral wind loading.

Answer : $:$ if $\sigma_{\mathrm{t}}<\sigma_{\mathrm{t} \_\mathrm{a} 500}$, "OK" , "No Good" $\quad$ Answer $=$ "OK" $\quad \begin{aligned} & \text { Beams are adequate per AISC 1989, Page } \\ & 5-40 .\end{aligned}$

$M_{b x}:=\frac{P_{\text {vert2 }}}{2} \cdot a \quad M_{b x}=187849$ in $\cdot \mathrm{lb}$

The maximum bending moment about the strong axis in the TS $7 \times 4 \times 3 / 8$ s.

$\mathrm{M}_{\text {by }}:=\frac{\mathrm{P}_{\text {horz2 }}}{2} \cdot \mathrm{a} \quad \mathrm{M}_{\text {by }}=70627$ in $\cdot \mathrm{lb}$

The maximum bending moment about the weak axis in the TS $7 \times 4 \times 3 / 8 s$.

$\sigma_{\mathrm{bx}}:=\frac{\mathrm{M}_{\mathrm{bx}}}{\mathrm{S}_{\mathrm{x}}} \quad \sigma_{\mathrm{bx}}=14909 \cdot \frac{\mathrm{lb}}{\mathrm{in}^{2}}$

The maximum strong axis bending stress. OK

Answer $:=$ if $\left(\sigma_{b x}<1.33 \cdot \sigma_{b_{-}} a 500\right.$, "OK" , "No Good" Answer = "OK"

Beams are adequate per AISC 1989, Page

$5-45$, Equation $F 1-1$. NOTE: use $1 / 3$ allowable stress increase per AISC 1989,

$\sigma_{\text {by }}:=\frac{\mathrm{M}_{\text {by }}}{S_{y}} \quad \sigma_{\text {by }}=7795 \cdot \frac{\mathrm{lb}}{\mathrm{in}^{2}}$

Page 5.30.

The maximum weak axis bending stress. OK

Answer $:=$ if $\sigma_{\text {by }}<1.33 \cdot \sigma_{\text {b_a500 }}$, "OK" , "No Good" Answer = "OK"

Beams are adequate per AISC 1989, Page 5-45, Equation F1-1. NOTE: use $1 / 3$ allowable stress increase per AISC 1989, Page 5.30.

Determine the maximum shear stress on the TS $7 \times 4 \times 3 / 8$ s.

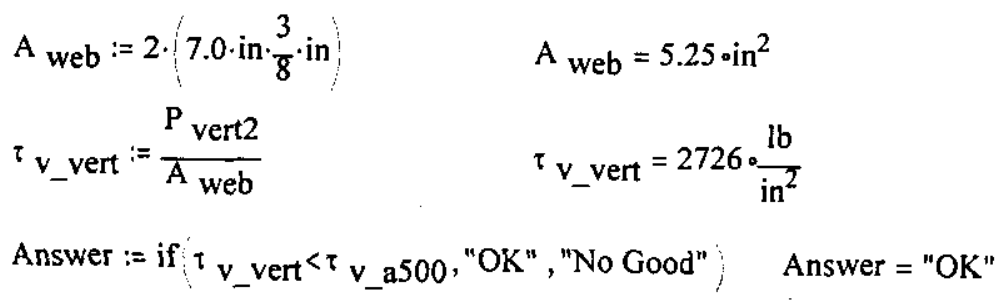

$A_{\text {flan }}:=2 \cdot 4.0 \cdot \mathrm{in} \cdot \frac{3}{8} \cdot \mathrm{in} \quad \mathrm{A}_{\text {flan }}=3 \cdot \mathrm{in}^{2}$

$\tau_{v_{-} \text {trans }}:=\frac{\frac{P_{\text {horz2 }}}{2}}{2 \cdot A_{\text {flan }}} \quad \tau_{v_{-} \text {trans }}=448 \cdot \frac{\mathrm{lb}}{\mathrm{in}^{2}}$

Answer $:=$ if $\tau_{v \_ \text {vert }}<\tau$ v_a500, "OK" , "No Good" $\quad$ Answer $=$ "OK"
Only the web will take shear in the vertical direction.

The maximum vertical shear stress. OK

Beams are adequate per AISC 1989, Page 5-49, Equation $\mathrm{F} 4-1$.

Only the flanges will carry the shear in the transversal direction.

The maximum transverse shear stress. OK

Beams are adequate per AISC 1989, Page 5-49, Equation F4-1.

Check interaction.

$$
\frac{\sigma_{\mathrm{t}}}{\sigma_{\mathrm{t}} \mathrm{as}_{00}}=0.013
$$

$\sigma_{\text {t_a500 }}$

$\frac{\sigma_{t}}{\sigma_{t \_a 500}}+\frac{\sigma_{b x}+\sigma_{b y}}{\sigma_{b \_a 500}}=0.761$
Since this is less than 0.15 , use the following to check interaction.

OK 
HNF-4320

Rev. 0

8.10

Determine the adequacy of the TS $7 \times 4 \times 3 / 8$ columns.

$\begin{array}{ll}b:=25 \cdot \text { in } & \text { See sketch on previous page. } \\ r:=1.57 \cdot \text { in } & \text { Radius of gyration. } \\ K:=1 & \\ 1:=24 \cdot \text { in }-7 \cdot \text { in } & l=17 \text { in } \quad \text { See drawing } \mathrm{H}-2-85633 \text { for length. }\end{array}$

$\frac{\mathrm{K} \cdot 1}{\mathrm{r}}=10.828 \quad$ Use 11 .

$\sigma_{\text {a_a } 500}:=29170 \cdot \frac{\mathrm{lb}}{\mathrm{in}^{2}} \quad$ The allowable axial compressive stress from AISC 1989, Table C-50, Page 3-17.

$\sigma_{a}:=\frac{\frac{P_{\text {vert2 }}}{2}}{A_{c}} \quad \sigma_{a}=976 \cdot \frac{\mathrm{lb}}{\mathrm{in}^{2}} \quad$ The maximum axial compressive stress. OK

Answer $:=$ if $\sigma_{a}<\sigma_{\text {a }}$ a500, "OK", "No Good" Answer $=$ "OK" Beams are adequate per AISC 1989, Page

$\mathrm{M}_{\mathrm{bx}}:=\frac{\mathrm{P}_{\text {vert2 }}}{2} \cdot \mathrm{a} \quad \mathrm{M}_{\mathrm{bx}}=187849 \mathrm{in} \cdot \mathrm{lb} \quad$ Maximum moment about the strong axis.

$\mathrm{P}_{\text {horz1 }}$ Maximum moment about the weak axis (to be $M_{\text {by }}:=\frac{M_{\text {by }}=34899 \mathrm{\circ in} \cdot \mathrm{lb}}{4} \cdot \mathrm{a} \quad \begin{aligned} & \text { conservative the longitudinal loading due to the } \\ & \text { core sample truck stopping is included). }\end{aligned}$

$\sigma_{b x}:=\frac{M_{b x}}{S_{x}} \quad \sigma_{b x}=14909 \cdot \frac{\mathrm{lb}}{\mathrm{in}^{2}} \quad$ The maximum strong axis bending stress. OK

Answer $:=$ if $\sigma_{b x}<\sigma_{b}$ a500, "OK", "No Good" Answer = "OK" Beams are adequate per AISC 1989, Page

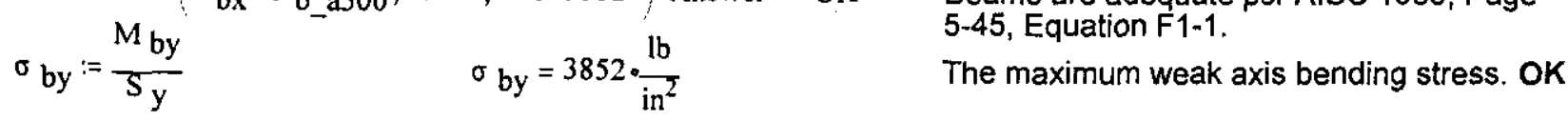

Answer $:=$ if $\sigma_{\text {by }}<\sigma_{\text {b_a500 }}$, "OK", "No Good" Answer = "OK" Beams are adequate per AISC 1989, Page

$\frac{\sigma_{\mathrm{a}}}{\sigma_{\mathrm{a} \_} \mathrm{a} 500}=0.033 \quad$ Since this is less than 0.15, use the following to check interaction.

$\frac{\sigma_{a}}{\sigma_{a \_} a 500}+\frac{\sigma_{b x}+\sigma_{b y}}{\sigma_{b \_} a 500}=0.651 \quad$ OK

8.11 Determine the adequacy of the fillet weld connecting the two TS $7 \times 4 \times 3 / 8$.

The weld connecting the TS $7 \times 4 \times 3 / 8$ to the $1 / 2$ in. base plate is the same size and will carry the same loads, therefore, these calculations will also check the TS to base plate weld. 
HNF-4320

Rev. 0

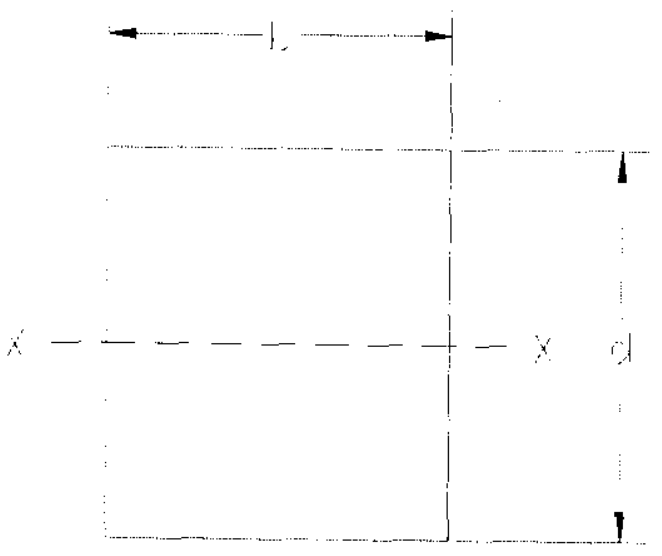

$$
\begin{aligned}
& \text { Weld Geometry: } \\
& \mathrm{b}:=7 \text { in Weld width. } \\
& d:=4 \text {.in Weld length. } \\
& \mathrm{w}_{\mathrm{a}}:=\frac{1}{4} \text {.in Weid size. } \\
& \sigma_{\text {base }}:=46000 \cdot \frac{\mathrm{lb}}{\mathrm{in}^{2}} \quad \text { Yield stress of the base metal. } \\
& \sigma_{\text {weld }}:=70000 \cdot \frac{\mathrm{lb}}{\mathrm{in}^{2}} \quad \text { Weld metal strength. } \\
& F_{x}:=\frac{P_{\text {horz2 }}}{4} \quad F_{y}:=0 \cdot 1 b \quad F_{z}:=\frac{P_{\text {vert2 }}}{2} \\
& M_{X}:=0 \cdot \text { in } \cdot 1 b \quad M_{y}:=\frac{P_{\text {vert }}}{4} \cdot a \quad M_{z}:=0 \cdot \text { in } \cdot 1 b
\end{aligned}
$$

Weld Properties Per Blodgett 1991

$$
\begin{array}{lll}
C_{x}:=\frac{b}{2} & C_{x}=3.5 \cdot i n & \text { The distance to the outer fiber in the x-direction. } \\
C_{y}:=\frac{d}{2} & C_{y}=2 \cdot i n & \text { The distance to the outer fiber in the } y \text {-direction. } \\
A_{w}:=2 \cdot(b+d) & A_{w}=22 \cdot i n & \text { The linear area of the weld. } \\
S_{w x}:=b \cdot d+\frac{d^{2}}{3} & S_{w x}=33.333 \cdot \mathrm{in}^{2} & \text { The linear section modulus about the } x \text {-axis. } \\
S_{w y}:=d \cdot b+\frac{b^{2}}{3} & S_{w y}=44.333 \cdot \mathrm{in}^{2} & \text { The linear section modulus about the } y \text {-axis. } \\
J_{w}:=\frac{(b+d)^{3}}{6} & J_{w}=221.833 \cdot \mathrm{in}^{3} & \text { The linear polar moment of inertia. }
\end{array}
$$

Linear Weld Stress:

$$
f_{w}:=\sqrt{\left.\left.\frac{F_{z}}{A_{w}}+\frac{M_{x}}{S_{w x}}+\frac{M_{y}}{S_{w y}}\right)^{2}+\frac{F_{x}}{A_{w}}+\frac{M_{z} \cdot C_{y}}{J_{w}}\right)^{2}+\left(\frac{F y}{A_{w}}+\frac{M_{z} \cdot C_{x}}{J_{w}}\right)^{2}} \quad f_{w}=2444.64 \cdot \frac{\mathrm{lb}}{\text { in }}
$$

Required Fillet Weld Size:

$$
\mathrm{w}_{r}:=\mathrm{if}\left[\frac{\mathrm{f}_{\mathrm{w}}}{0.4 \cdot \sigma_{\text {base }}} \leq \frac{\mathrm{f}_{\mathrm{w}}}{0.707 \cdot 0.3 \cdot \sigma_{\text {weld }}}, \frac{\mathrm{f}_{\mathrm{w}}}{0.4 \cdot \sigma_{\text {base }}}, \frac{\mathrm{f}_{\mathrm{w}}}{0.707 \cdot(0.3) \cdot \sigma_{\text {weld }}}\right] \quad \mathrm{w}_{\mathrm{r}}=0.133 \text { in }
$$

0.707 is for shear through throat of fillet weld, 0.3 is allowable stress reduction factor for shear through throat of fillet weld and 0.4 is for shear on base metal. See AISC 1989, Table J2.5, Page 5-70.

The Margin of Safety:

MS : $=\frac{w_{a}}{w_{r}}-1$

$$
\mathrm{MS}=0.882
$$

OK 
HNF -4320

Rev. 0

8.12 Determine the adequacy of the $7 / 16$ in $\times 1 \mathrm{ft}$ plate and angle connecting the two $\mathrm{W} 8 \times 18 \mathrm{~s}$ to the TS $7 \times 4 \times 3 / 8$.
$A_{c}:=\frac{7}{16} \cdot$ in $+\frac{3}{8} \cdot$ in $\cdot 24.75 \cdot$ in
$A_{c}=20.109 \mathrm{oin}^{2}$
Combined cross sectional area of
$\tau_{v}:=\frac{P_{\text {vert2 }}}{A_{c}}$
$\tau_{v}=711.722 \cdot \frac{\mathrm{lb}}{\mathrm{in}^{2}}$
Answer := if $\tau^{\tau} v^{<\tau} v_{-} a 36$, "OK", "No Good" Answer = "OK"
Beams are adequate per AISC 1989, Page 5-49, Equation F4-1.

8.13 Determine the adequacy of the ramp. Wind loads are not to be considered in the analysis of the ramp.
$\mathrm{A}_{\mathrm{c}}:=2 \cdot 2.86 \cdot \mathrm{in}^{2}$
$\mathrm{A}_{\mathrm{c}}=5.72 \cdot \mathrm{in}^{2}$
Cross sectional area of an $L 4 \times 4 \times 3 / 8$.

$1:=25 \cdot$ in

Maximum ramp column length from $\mathrm{H}-2-85633$

$\mathrm{K}:=1$

$r:=1.23 \cdot$ in

Radius of gyration.

$\frac{\mathrm{K} \cdot 1}{\mathrm{r}}=20.325$

Use 21

$\mathrm{S}:=2 \cdot 1.52 \cdot \mathrm{in}^{3}$

$L 4 \times 4 \times 3 / 8$ section modulus.

$\sigma_{a_{-} a 36}:=20540 \cdot \frac{\mathrm{lb}}{\mathrm{in}^{2}} \quad$ Allowable compressive stress from AlsC 1989, Table C-36, Page 3-16.

Check the L. $4 \times 4 \times 3 / 8 \mathrm{in}$. columns for adequacy.

$\sigma_{\mathrm{a}}:=\frac{\mathrm{P}_{\text {rear }}}{2 \cdot \mathrm{A} \cdot \mathrm{c}} \quad \sigma_{\mathrm{a}}=1836 \cdot \frac{\mathrm{lb}}{\mathrm{in}^{2}}$

Maximum axial compressive stress. NOTE: tire load is spread evenly over all 2 columns.

Answer $:=$ if $\sigma_{a}<\sigma_{a_{-}}$a36,, "OK", "No Good" Answer $=$"OK"

Check the maximum shear and bending in the $L 4 \times 4 \times 3 / 8$.

$\mathrm{L}:=48$.in

Distance between ramp columns.

$\begin{array}{ll}M_{\max }:=\frac{\frac{P_{\text {vert }}}{4} \cdot L}{4} & M_{\max }=42937 \text { in } \cdot 1 b \\ \sigma_{b}:=\frac{M_{\max }}{S} & \sigma_{b}=14124 \cdot \frac{\mathrm{lb}}{\mathrm{in}^{2}}\end{array}$

Answer $:=$ if $\sigma_{b}<\sigma_{b \_}$a36,, "OK", "No Good" Answer = "OK"

$\tau_{v}:=\frac{P_{\text {horz2 }}}{2 \cdot A_{c}} \quad \tau_{v}=470 \cdot \frac{\mathrm{lb}}{\mathrm{in}^{2}}$

The maximum moment in a single $L .4 \times 4 \times 3 / 8$ treating it as a simply supported beam.

Maximum bending stress. OK

Beams are adequate per AISC 1989, Page 5-45, Equation F1-1.

Maximum shear on a single $L 4 \times 4 \times 3 / 8$

Answer : $=$ if $\tau_{v^{<}<\tau_{-} \text {a36 }}$, "OK", "No Good": Answer = "OK"

Beams are adequate per AISC 1989, Page 5-49, Equation F4-1. 
HNF-4320

Rev. 0

8.15 Determine the adequacy of the weld connecting a ramp beam to a ramp column.

This set of calculations determines the adequacy of the weld configuration show in the figure below. The actual weld configuration is different but this is an adequate representation of it and is conservative.

Per AISC 1989, the required weld size checks both the shear on the base metal and the shear through the throat of the fillet weld to ensure that failure will not occur.

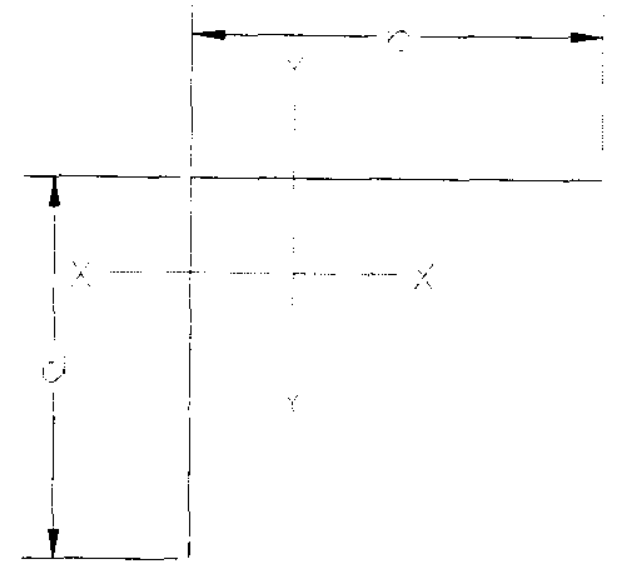

\section{Weld Geometry:}

$b:=1$ in Weld width.

d := $1 \cdot$ in $\quad$ Weld length.

$\mathrm{w}_{\mathrm{a}}:=\frac{1}{4} \cdot$ in

The actual weld size.

$\sigma_{\text {base }}:=36000 \cdot \frac{\mathrm{lb}}{\mathrm{in}^{2}} \quad$ Yield stress of the base metal.

$\sigma_{\text {weld }}:=70000 \cdot \frac{\mathrm{lb}}{\mathrm{in}^{2}} \quad$ Weld metal strength.

Connection Loads:

$\begin{array}{lll}F_{X}:=0 \cdot \mathrm{lb} & F_{y}:=0 \cdot 1 b & F_{z}:=\frac{P_{\text {rear }}}{4} \\ M_{X}:=0 \cdot \mathrm{in} \cdot \mathrm{lb} & M_{y}:=0 \cdot \mathrm{in} \cdot \mathrm{lb} & M_{z}:=0 \cdot \mathrm{in} \cdot \mathrm{lb}\end{array}$

Weid Properties per Blodgett 1991

$C_{x}:=\frac{d^{2}}{2 \cdot(b+d)} \quad C_{x}=0.25$ in

The distance to the outer fiber in the $\mathrm{x}$-direction.

$C_{y}:=\frac{b^{2}}{2 \cdot(b+d)}$

$C_{y}=0.25 \cdot \mathrm{in}$

The distance to the outer fiber in the y-direction.

$A_{w}:=b+d$

$A_{w}=2$ oin

The linear area of the weld.

$S_{w x}:=\operatorname{if}\left[\frac{4 \cdot b \cdot d+d^{2}}{6}<\frac{d^{2} \cdot(4 \cdot b+d)}{6 \cdot(2 \cdot b+d)}, \frac{4 \cdot b \cdot d+d^{2}}{6}, \frac{d^{2} \cdot(4 \cdot b+d)}{6 \cdot(2 \cdot b+d)}\right]$

$\mathrm{S}_{\mathrm{wx}}=0.278 \cdot \mathrm{in}^{2}$

$S_{w y}:=\operatorname{if}\left[\frac{4 \cdot d \cdot b+b^{2}}{6}<\frac{b^{2} \cdot(4 \cdot d+b)}{6 \cdot(2 \cdot d+b)}, \frac{4 \cdot d \cdot b+b^{2}}{6}, \frac{b^{2} \cdot(4 \cdot d+b)}{6 \cdot(2 \cdot d+b)}\right]$

$J_{w}:=\frac{(b+d)^{4}-6 \cdot b^{2} \cdot d^{2}}{12 \cdot(b+d)}$
$S_{w y}=0.278 \operatorname{oin}^{2}$

The linear section modulus about the $x$-axis.

The linear section modulus about the $y$-axis.

$\mathrm{J}_{\mathrm{w}}=0.417 \mathrm{in}^{3} \quad$ The linear polar moment of inertia

Linear Weld Stress:

$f_{w}:=\sqrt{\left.\frac{F_{z}}{A_{w}}+\frac{M_{x}}{S_{w x}}+\frac{M_{y}}{S_{w y}}\right)^{2}+\frac{F_{x}}{A_{w}}+\frac{M_{z} \cdot C_{y}}{J_{w}}+\frac{F_{y}}{A_{w}}+\frac{M_{z} C_{x}}{J_{w}}} \quad f_{w}=2625 \cdot \frac{\mathrm{lb}}{\text { in }}$

Required Fillet Weld Size: 
HNF-4320

Rev. 0

$w_{r}:=$ if $\left[\frac{f_{w}}{0.4 \cdot \sigma_{\text {base }}} \leq \frac{f_{w}}{0.707 \cdot 0.3 \cdot \sigma_{\text {weld }}}, \frac{f_{w}}{0.4 \cdot \sigma_{\text {base }}}, \frac{f_{w}}{0.707 \cdot(0.3) \cdot \sigma_{\text {weld }}}\right]$

$\mathrm{w}_{\mathrm{r}}=0.177$ in

0.707 is for shear through throat of fillet weld, 0.3 is allowable stress reduction factor for shear through throat of fillet weld and 0.4 is for shear on base metal. See AISC 1989, Table J2.5, Page 5-70.

The Margin of Safety:

MS : $: \frac{w_{a}}{w_{I}}-1$

$\mathrm{MS}=0.414$

OK 
HNF-4320

Rev. 0

1.0 OBJECTIVE This set of calculations sizes and determines the adequacy of bolts attaching the Core Sampling platform to the foundation provided by FDNW. The foundation and platform combination is provided to span tank 241-Z-361 without side loading the tank walls.

\subsection{DESIGN INPUTS}

2.1 Design drawing $\mathrm{H}-2-85633$

\subsection{ASSUMPTIONS}

3.1 Due to the slotted holes in the base plate (see figure below), only two bolts on any leg will be assumed to support any lateral loading.

3.2 Due to the design of the foundation, moment frame with diagonal bracing on all sides, no moments shall be transferred to the foundation

\subsection{METHODS OF ANALYSIS (Hand Caiculations)}

\subsection{REFERENCES}

5.1 AISC, 1989, Manual of Steel Construction, 9th Edition, American Institute of Steel Construction, Chicago lilinois.

5.2 WHC, 1995, Structural Evaluation for the Core Sampling Trucks RMCS Operations 200 Area, WHC-SD-WM-DA-215 Rev. 0. Westinghouse Hanford Company.

6.0 FINDINGS AND CONCLUSIONS (8) 3/4" A325 bolts $\times 3^{n}$ long minimum shall be used to attach the platform to the foundation. Calculations below determined that the bolts are adequate for attaching the platform to the foundation.

\subsection{CALCULATIONS}

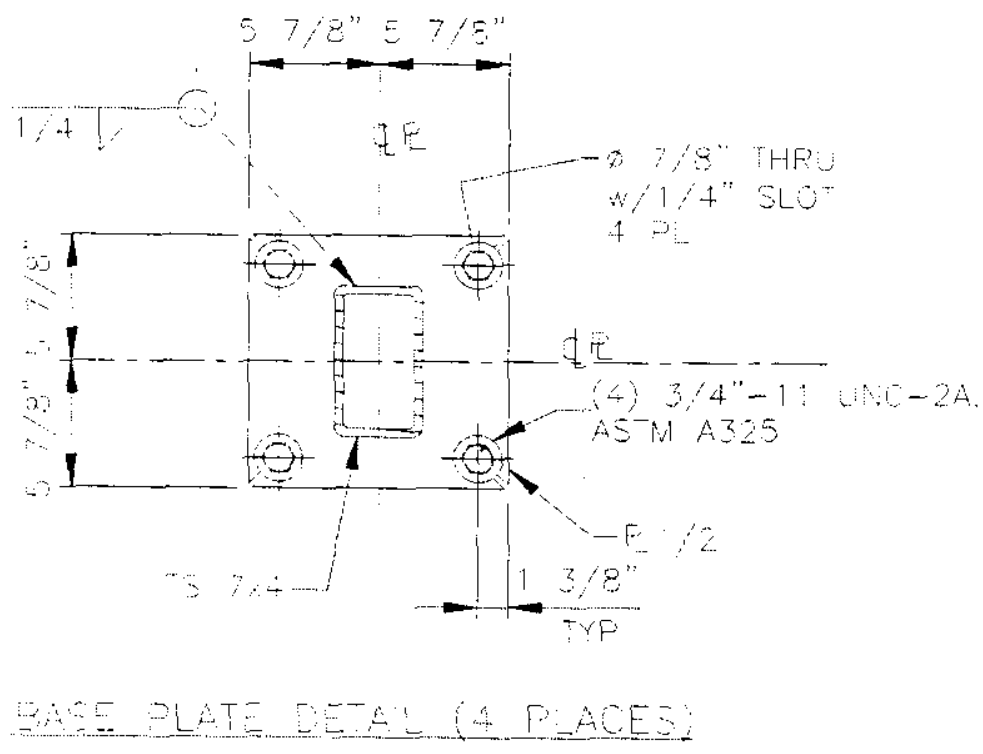

Given the 7/8" dia slotted holes shown in the figure on the previous page, use ASTM A325 3/4" bolts $x$ for attaching the platform to the foundation.

$A_{k}:=.302 \cdot i^{2} \quad$ The minimum root area for a 3/4" bolt (AISC 1989, Page 4-147). $\tau$ allow $:=21000 \cdot \frac{\mathrm{lb}}{\mathrm{in}^{2}} \quad \begin{aligned} & \text { The maximum shear on the bolt (AISC 1989, Table 2, Page 5-269. Bolt threads are assumed to } \\ & \text { be in the shear plane for (conservative). }\end{aligned}$ 
HNF -4320

Rev. 0

$\sigma_{\mathrm{t} \text { allow }}:=44000 \cdot \frac{\mathrm{lb}}{\mathrm{in}^{2}}$ The maximum tensile stress on an A325 bolt per AISC 1989, Table 2, Page 5-269.

From WHC, 1995, Page A12, the wind loading on the core sample truck will not cause overturning of the core sample truck. For this reason, there is no tensile loading on the bolted connection.

$\mathrm{F}_{\mathrm{w}}:=\mathrm{P}_{\mathrm{W}_{-} 85} \quad \mathrm{~F}_{\mathrm{W}}=5381 \mathrm{lb} \quad$ Loading due to $85 \mathrm{mph}$ wind.

$\mathrm{F}_{\max }:=\mathrm{F}_{\mathrm{W}} \quad \mathrm{F}_{\max }=5381.113 \mathrm{elb} \quad$ Maximum force on the two bolt pattern.

$\tau_{\text {act }}:=\frac{F_{\max }}{4 \cdot A_{\mathrm{k}}} \quad \tau_{\text {act }}=4454.564 \cdot \frac{\mathrm{lb}}{\mathrm{in}^{2}} \quad \begin{aligned} & \text { Actual bolt stress. Assumed force is distributed on two legs of } \\ & \text { platform (conservative). }\end{aligned}$

MS : $: \frac{{ }^{\tau} \text { allow }}{{ }^{\tau} \text { act }}-1 \quad$ MS $=3.714 \quad$ Answer $:=$ if(MS $\geq 0$, "OK", "No Good" ) Answer $=$ "OK"

Determine the maximum tensile loading on the $3 / 4$ " bolts.

$F_{\text {bolt }}:=\frac{\frac{P_{\text {vert } 2}}{2} \cdot \mathrm{a}}{\frac{2}{2 \cdot 9.5 \cdot \mathrm{in}}}$

$F_{\text {bolt }}=9886.771 \mathrm{lb} \quad$ The force on each bolt.

$\sigma_{t}:=\frac{F_{\text {bolt }}}{A_{k}}$

$\sigma_{\mathrm{t}}=32738 \cdot \frac{\mathrm{lb}}{\mathrm{in}^{2}}$

MS : $=\frac{\sigma_{t_{\text {_allow }}}}{\sigma_{\mathrm{t}}}-1 \quad \mathrm{MS}=0.344$

Answer := if(MS $\geq 0$, "OK" , "No Good" )

Answer $=$ "OK" 
HNF-4320

Rev. 0

1.0 OBJECTIVE This set of calculations determines the adequacy of lateral bracing. The foundations that this platform will be placed on, when sampling from tank 241-Z-361, are not suitable for resisting the induced moment from the platforms. For this reason, the platforms must be stiffened to resist the induced moment. Diagonal bracing on both the lateral and longitudinal sides shall be used to resist the induced moments. Also, tie rods shall be added in the longitudinal direction to the base of each leg for increased stiffness. The diagonal bracing and tie rod designs are shown on ECN 651132.

\subsection{DESIGN INPUTS}

2.1 Design drawing $\mathrm{H}-2-85633$

2.2 Engineering Change Notice, 639132 and 651132.

\subsection{ASSUMPTIONS}

4.0 METHODS OF ANALYSIS (Hand Calculations)

\subsection{REFERENCES}

5.1 AISC, 1989, Manual of Steel Construction, 9th Edition, American Institute of Steel Construction, Chicago Illinois.

5.2 Blodgett, OW, 1991, Design of Welded Structures, Fourteenth Printing, The James F. Lincoln Arc Welding Foundation, Cleveland, Ohio.

6.0 FINDINGS AND CONCLUSIONS The force applied to the diagonal bracing is $3000 \mathrm{lb}$ and the force applied to the tie rod is $14300 \mathrm{lb}$. The calculations determined that the diagonal bracing and longitudinal tie rods are adequate as design.

\subsection{CALCULATIONS}

7.1 Properties, Geometry and Loads.

$\sigma_{y}:=36000 \cdot \frac{\mathrm{lb}}{\mathrm{in}^{2}} \quad$ Yield stress of A36 carbon steel.

$\mathrm{L}:=20.5 \cdot \mathrm{ft} \quad$ Length of Characterization platform (H-2-85633).

$\mathrm{h}:=25 \cdot \mathrm{in} \quad$ Height of Characterization platform $(\mathrm{H}-2-85633)$.

$\mathrm{w}:=10.75 \cdot \mathrm{ft} \quad$ Width of Characterization platform $(\mathrm{H}-2-85633)$.

$\mathrm{F}_{\mathrm{L}}:=\frac{5400 \cdot \mathrm{lb}}{2} \quad$ Maximum longitudinal force due to sudden stopping of core sample truck.

$\mathrm{F}_{\mathrm{w}}:=\frac{5400 \cdot \mathrm{lb}}{2} \quad$ Maximum lateral force due to wind.

7.2 Determine internal force carried by the wire rope diagonal bracing.
$\theta_{\mathrm{L}}:=\operatorname{atan}: \frac{\mathrm{L}}{\mathrm{h}}$
$\theta_{\mathrm{L}}=84.197 \cdot \mathrm{deg}$
Angle of diagonal bracing on longitudinal side.
$\theta_{\mathrm{w}}:=\operatorname{atan}\left(\begin{array}{l}\mathrm{w} \\ \mathrm{h}\end{array}\right.$
$\theta_{\mathrm{W}}=79.03 \cdot \mathrm{deg}$
Angle of diagonal bracing on lateral side.
$F_{L_{-} \text {diag }}:=\frac{F_{L}}{\left.\sin ^{\prime} \theta_{L}\right)}$
$F_{L_{-} \text {diag }}=2713.907 \cdot \mathrm{ib}$
Maximum diagonal force required to resist longitudinal loading. 
HNF-4320

Rev. 0

$\mathrm{F}_{\mathrm{w}_{-} \text {diag }}:=\frac{\mathrm{F}_{\mathrm{w}}}{\sin \theta_{\mathrm{W}}} \quad \mathrm{F}_{\mathrm{W}_{-} \text {diag }}=2750.236 \mathrm{elb} \quad$ Maximum diagonal force required to resist lateral loading due to win $F:=3000 \cdot \mathrm{lb} \quad$ Use maximum diagonal force of $3000 \mathrm{lbf}$ for design purposes.

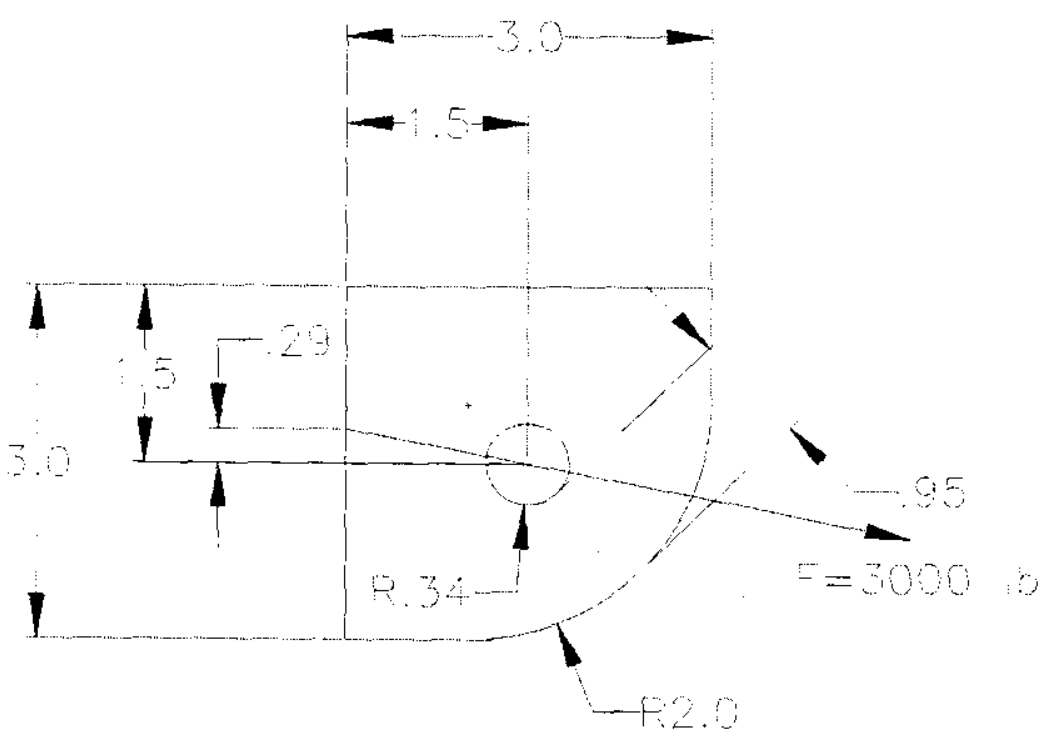

7.3 Determine adequacy of the upper diagonal bracing shackel hole to resist tear out of a $1 / 2$ " dia shackle pin subject to a $3000 \mathrm{lb}$ load as shown.
$\mathrm{A}_{\mathrm{c}}:=\frac{1}{2} \cdot \mathrm{in} \cdot 95 \cdot \mathrm{in}$
$A_{c}=0.475 \cdot \mathrm{in}^{2}$
Cross sectional area between hole and 2 in radius.
$\tau:=\frac{\mathrm{F}}{\mathrm{A}_{\mathrm{c}}}$
$\tau=6315.789 \cdot \frac{\mathrm{lb}}{\mathrm{in}^{2}}$
Actual shear stress.
$\tau^{\text {allow }}:=.4 \cdot \sigma_{\mathrm{y}}$
$\tau$ allow $=14400 \cdot \frac{\mathrm{lb}}{\mathrm{in}^{2}}$
Allowable shear stress from AISC 1989.
MS : $=\frac{\tau \text { allow }}{\tau}-1$
$\mathrm{MS}=1.28$
Margin of safety.
$\mathrm{e}:=.292 \cdot$ in
Eccentricity caused by force not passing directly through weld centroid.

7.4 Determine adequacy of weld attaching shackle attachment to platform.

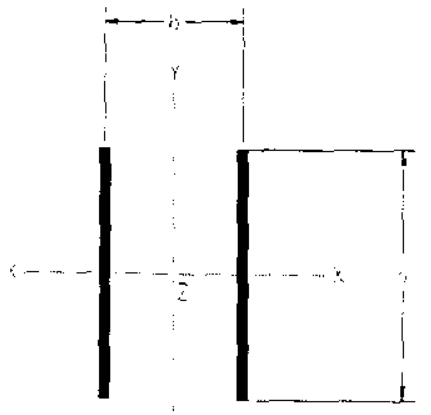

$$
\begin{array}{ll}
\begin{array}{ll}
\text { Weld Geometry. } \\
\mathrm{b}:=\frac{1}{2} \cdot \text { in }
\end{array} & \text { The width of the weld. } \\
\mathrm{d}:=3 \cdot \mathrm{in} & \text { The length of the weld. } \\
\mathrm{w}_{\mathrm{a}}:=\frac{1}{4} \cdot \text { in } & \text { The actual weld size. } \\
\sigma_{\text {base }}:=36000 \cdot \frac{\mathrm{lb}}{\mathrm{in}^{2}} & \text { Yield stress of the base metal. } \\
\sigma_{\text {weld }}:=70000 \cdot \frac{\mathrm{lb}}{\mathrm{in}^{2}} & \text { Weld metal Strength. }
\end{array}
$$


HNF -4320

Rev. 0

Connection Loads:

Weld Properties per Blodgett 1991:

$$
\begin{array}{lll}
F_{X}:=0 \cdot 1 b & F_{y}:=F \cdot \sin (11 \cdot \mathrm{deg}) & F_{z}:=F \cdot \cos (11 \cdot d e g) \\
M_{X}:=F \cdot e & M_{y}:=0 \cdot i n \cdot l b & M_{z}:=0 \cdot \text { in } \cdot l b
\end{array}
$$

$C_{\mathbf{X}}:=\frac{b}{2}$

$$
C_{x}=0.25 \text { in }
$$

$C_{y}:=\frac{d}{2}$

$C_{y}=1.5$ in

$A_{w}:=2 \cdot d$

$A_{w}=6$ in

$S_{w x}:=\frac{d^{2}}{3}$

$S_{w x}=3 \cdot$ in $^{2}$

$\mathrm{S}_{\mathrm{wy}}=1.5 \cdot \mathrm{in}^{2}$

$J_{w}:=\frac{d \cdot 3 \cdot b^{2}+d^{2}}{6} \quad J_{w}=4.875 \cdot \mathrm{in}^{3} \quad$ The linear polar moment of inertia.

The distance to the outer fiber in the x-direction.

The distance to the outer fiber in the $y$-direction.

The linear area of the weld.

The linear section modulus about the $x$-axis.

The linear section modulus about the $y$-axis.

Linear Weld Stress:

$f_{w}:=\sqrt{\left.\frac{F_{z}}{A_{w}}+\frac{M_{x}}{S_{w x}}+\frac{M_{y}}{S_{w y}}\right)^{2}+\frac{F x}{A_{w}}+\frac{\left.M_{z} \cdot C_{y}\right)^{2}}{J_{w}}+\left(\frac{F_{y}}{A_{w}}+\frac{M_{z} C_{x}}{J_{w}}\right)^{2}} \quad f_{w}=788.606 \circ \frac{\mathrm{lb}}{\mathrm{in}}$

Required Weld Size:

$\mathrm{w}_{\mathrm{r}}:=\operatorname{if}\left[\frac{\mathrm{f}_{\mathrm{w}}}{0.4 \cdot \sigma_{\text {base }}} \leq \frac{\mathrm{f}_{\mathrm{w}}}{0.707 \cdot 0.3 \cdot \sigma_{\text {weld }}}, \frac{\mathrm{f}_{\mathrm{w}}}{0.4 \cdot \sigma_{\text {base }}}, \frac{\mathrm{f}_{\mathrm{w}}}{0.707 \cdot(0.3) \cdot \sigma_{\text {weld }}}\right] \quad \mathrm{w}_{\mathrm{r}}=0.053 \mathrm{oin}$

0.707 is for shear through throat of fillet weld, 0.3 is allowable stress reduction factor for shear through throat of fillet weld and 0.4 is for shear on base metal. See AISC 1989, Table $J 2.5$, Page 5-70.

The margin of safety:

MS : $=\frac{w_{a}}{w_{r}}-1$

MS $=3.707$

OK 
HNF-4320

Rev. 0

7.5 Determine the adequacy of the lower diagonal bracing hole and tie rod hole.

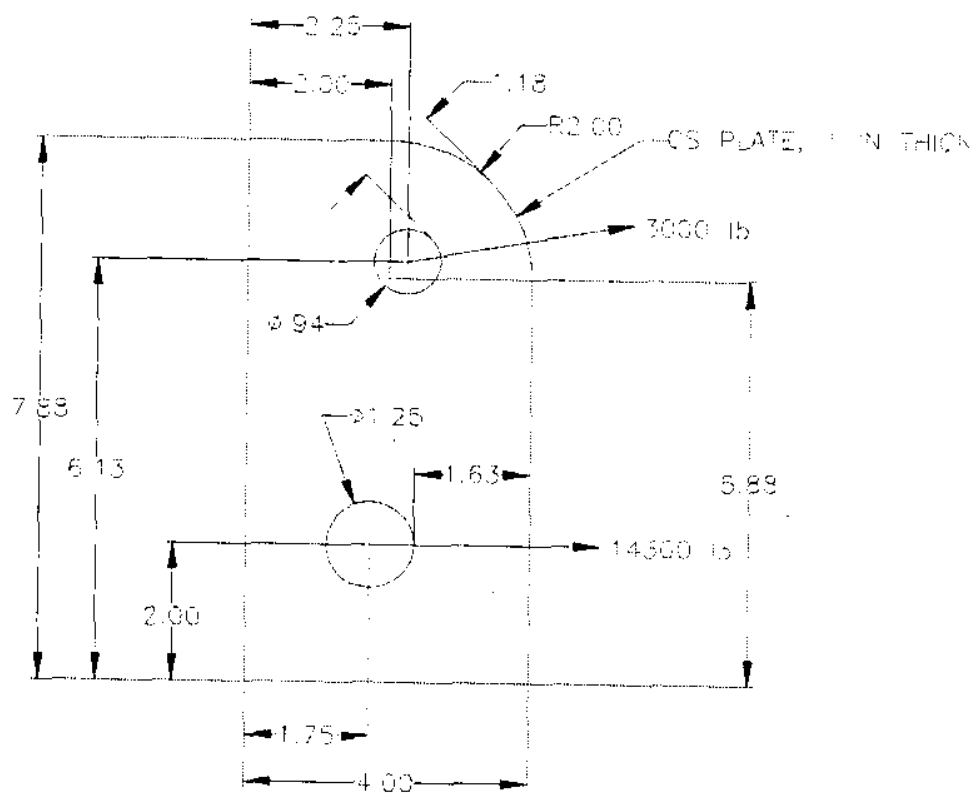

Based on the calculations above the lower shackle hole for diagonal bracing is adequate (dimensions and loading are identical). The weld will be checked after calculating the adequacy of the tie rod hole.

7.6 Determine the adequacy of the tie rod hole. The foundation designed by Fluor Daniel Northwest cannot withstand large moments, for this reason tie rods are installed to withstand the moments due to eccentric loading of the TS $7 \times 4 \times 3 / 8$ columns.

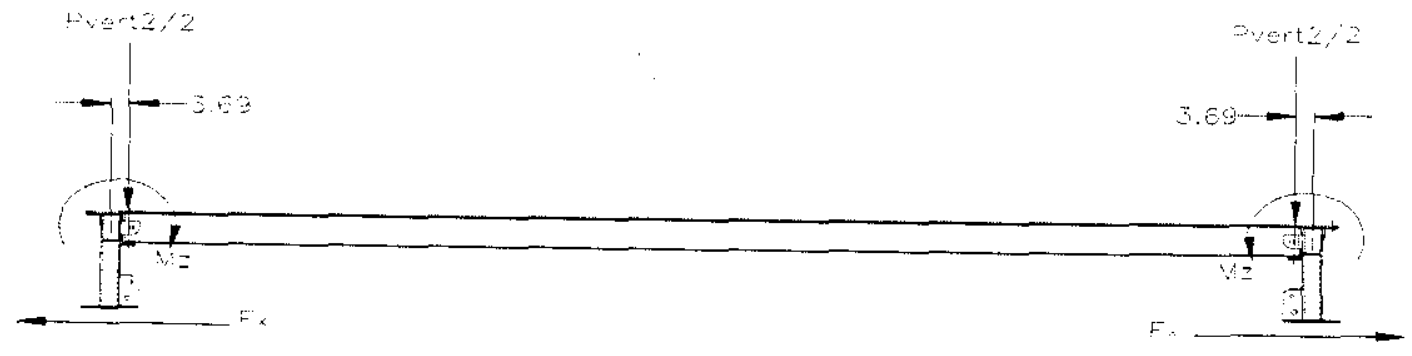

$e_{4}:=3.69 \cdot$ in

$M_{z}:=\frac{\frac{P_{\text {vert2 }}}{2} \cdot e_{4}}{4}$

$M_{z}=6602 \cdot$ in $\cdot \mathrm{lb}$

Moment in column 
HNF-4320

Rev. 0

This moment is too small. Consider the shear connection to be a moment connection and use a $10,000 \mathrm{lb}$ load. This is conservative.

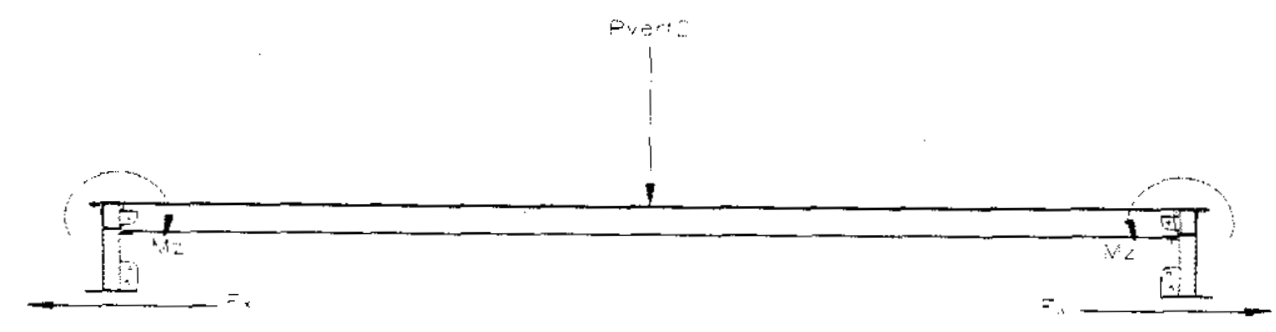

P vert_temp $:=10000 \cdot \mathrm{lb} \quad \begin{aligned} & \text { Vertical loading on column for structural analysis of tie rod and associated } \\ & \text { equipment. }\end{aligned}$

$M_{z}:=\frac{P_{\text {vert_temp }} \cdot L}{8} \quad M_{z}=307500 \cdot$ in $\cdot$ ib $\quad$ Moment on column.

$F_{x}:=\frac{M_{z}}{25 \cdot \text { in }-\frac{7 \cdot i^{2}}{2}} \quad F_{x}=14302 \mathrm{lb} \quad$ Force at base to resist moment.

Determine the adequacy of the tie rod hole.

$A_{c}:=1.625 \cdot \mathrm{in} \cdot 1 \cdot$ in $\quad$ Cross sectional area between the hole and the outer edge.

$\tau_{\text {hole }}:=\frac{F_{x}}{A_{c}} \quad \tau_{\text {hole }}=8801 \cdot \frac{\mathrm{lb}}{\mathrm{in}^{2}}$ Answer : $:$ if $\tau$ hole ${ }^{<\tau} v_{-}$a 36, "OK" , "No Good" Answer = "OK" $\quad \begin{aligned} & \text { Hole will resist tear-out of shackle } \\ & \text { supporting the tie rod. }\end{aligned}$

Determine the adequacy of the tie rod.

$\mathrm{D}:=1.25$. in Diameter of tie rod.
A c $\_$tie $:=\frac{\pi}{4} \cdot \mathrm{D}^{2}$
$A_{c_{-} \text {tie }}=1.227 \operatorname{ain}^{2}$
Cross sectional area of tie rod.

$\sigma_{t}:=\frac{F_{x}}{A_{c_{-} t i e}}$

$\sigma_{t}=11654.583 \cdot \frac{\mathrm{lb}}{\mathrm{in}^{2}}$

Tensile load on tie rod.

Answer := if $\sigma_{\mathbf{t}}<\sigma_{\mathrm{t}} \mathrm{a} 36$, , OK" , "No Good" $\quad$ Answer = "OK" $\quad \begin{aligned} & \text { Hole will resist tear-out of shackle } \\ & \text { supporting the tie rod. }\end{aligned}$

Determine the adequacy of associated rigging hardware.

Wire Cables: Wire cables are to be used for all diagonal bracing and shall be capable of supporting a 3000 Ib. load. Cable size shall be 1/4" Wire Cable, 6 × 19, RRL, IWRC.

Shackles: A $43 / 4$ ton shackle is used for diagonal bracing $(9500 \mathrm{lb})$ and the maximum diagonal bracing loading is $3000 \mathrm{lb}$, therefore, the shackles are adequate.

Turnbuckles: The turnbuckles are rated at $15,200 \mathrm{lb}$. This is greater than the axial load of $14,300 \mathrm{lb}$, therefore, the shackles are adequate.

NOTE: all of these items have a proof strength of greater than or equal to two (2). 
HNF-4320

Rev. 0

7.7 Determine the adequacy of the weld attaching the shackle pin plate to the TS $7 \times 4 \times 3 / 8$.

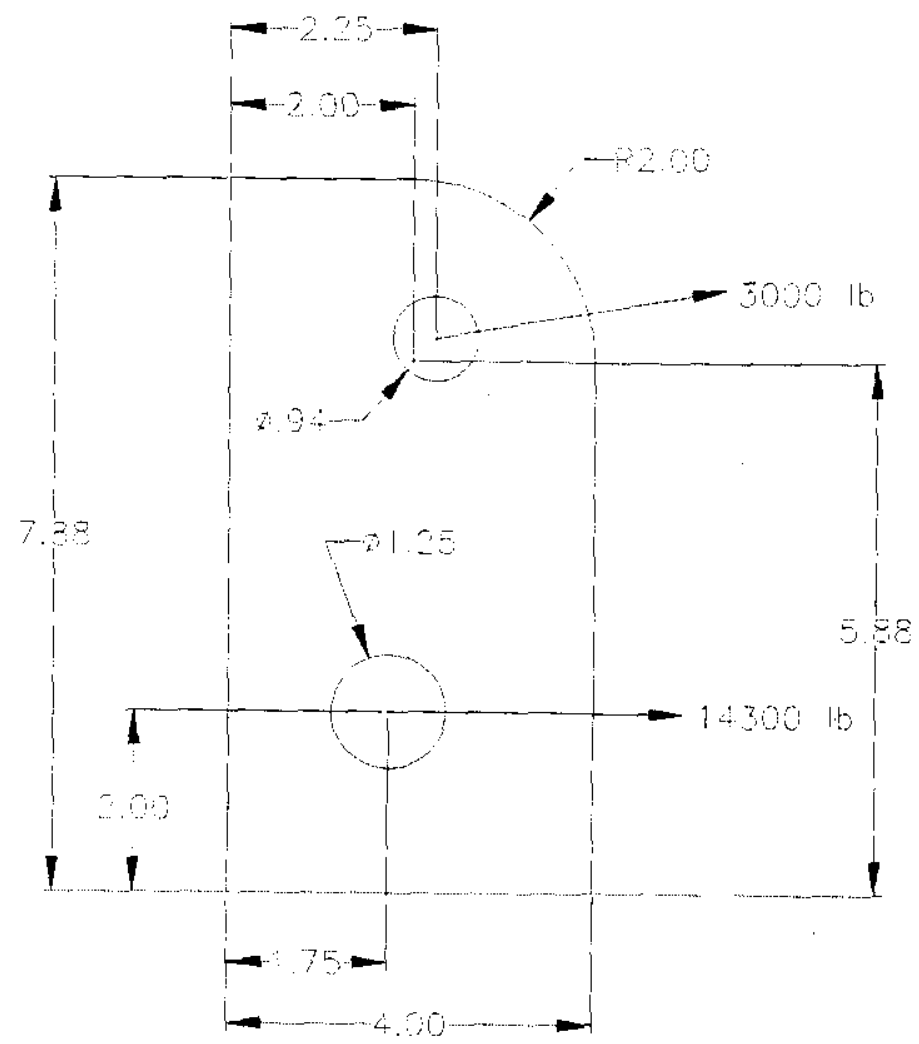

Determine the location of the weld centroid.

$d:=3.875 \cdot$ in

Length of weld in the horizontal direction. Note: plate is longer than base plate.

$\mathrm{b}:=7.88 \cdot \mathrm{in}$

Length of weld in the vertical direction.

$N x:=\frac{d^{2}}{2 \cdot(b+d)}$

$\mathrm{Nx}=0.639$ oin

Distance from bottom to $\mathrm{Cg}$ of weld.

$\mathrm{Ny}:=\frac{\mathrm{b}^{2}}{2 \cdot(\mathrm{b}+\mathrm{d})}$

$\mathrm{Ny}=2.641$ in

Distance from left side to $\mathrm{Cg}$ of weld.

Calculate the forces and moments on weld centroid.

$$
\begin{aligned}
& F_{\text {horz }}:=F_{X}+F \cdot \cos (11 \cdot \mathrm{deg}) \quad F_{\text {horz }}=17247.207 \mathrm{lb} \quad \text { Horizontal Loading on the plate. } \\
& \mathrm{F}_{\text {vert }}:=\mathrm{F} \cdot \sin (11 \cdot \mathrm{deg}) \quad \mathrm{F}_{\text {vert }}=572.427 \mathrm{lb} \quad \text { Vertical Loading on the plate. } \\
& M_{z_{-} \text {weld }}:=F_{X^{\prime}} \cdot(N y-2 \cdot i n)+F \cdot \cos (11 \cdot d e g) \cdot(5 \cdot 88 \cdot \text { in }-N y)+F \cdot \sin (11 \cdot d e g) \cdot(4 \cdot \text { in }-N x) \\
& M_{z_{-} \text {weld }}=20632.535 \cdot \mathrm{in} \cdot \mathrm{lb}
\end{aligned}
$$


HNF -4320

Rev. 0

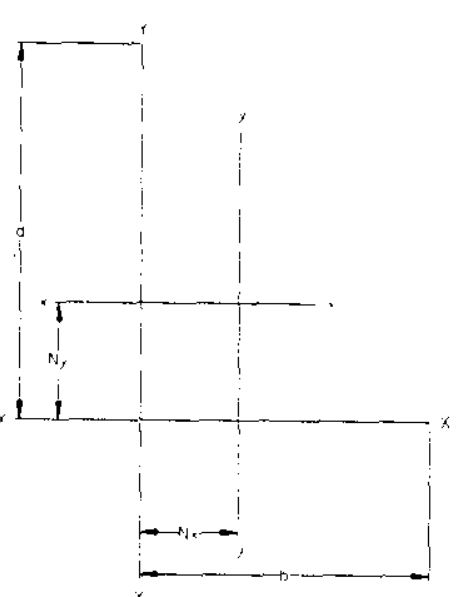

Weld Properties per Blodgett 1991

$$
\begin{array}{lll}
C_{x}:=\frac{d^{2}}{2 \cdot(b+d)} & C_{x}=2.641 \text { in } & \text { The distance to the outer fiber } \\
C_{y}:=\frac{b^{2}}{2 \cdot(b+d)} & C_{y}=0.639 \text { in } & \text { The distance to the outer fiber } \\
A_{w}:=2 \cdot(b+d) & A_{w}=23.51 \cdot \text { in } & \text { The linear area of the weld. } \\
S_{w x}:=2 \cdot i f\left[\frac{4 \cdot b \cdot d+d^{2}}{6}<\frac{d^{2} \cdot(4 \cdot b+d)}{6 \cdot(2 \cdot b+d)}, \frac{4 \cdot b \cdot d+d^{2}}{6}, \frac{d^{2} \cdot(4 \cdot b+d)}{6 \cdot(2 \cdot b+d)}\right] S_{w x}=30.961 \cdot i^{2}
\end{array}
$$$$
S_{\text {wy }}:=2 \cdot i f\left[\frac{4 \cdot d \cdot b+b^{2}}{6}<\frac{b^{2} \cdot(4 \cdot d+b)}{6 \cdot(2 \cdot d+b)}, \frac{4 \cdot d \cdot b+b^{2}}{6}, \frac{b^{2} \cdot(4 \cdot d+b)}{6 \cdot(2 \cdot d+b)}\right] S_{w y}=9.023 \cdot \operatorname{in}^{2}
$$$$
J_{w}:=2 \cdot \frac{(b+d)^{4}-6 \cdot b^{2} \cdot d^{2}}{12 \cdot(b+d)}
$$$$
J_{W}=191.399{\text { : } \mathrm{in}^{3}}^{3}
$$

\section{Weld Geometry:}

$$
\begin{array}{ll}
\mathrm{b}:=3.875 \cdot \mathrm{in} & \text { Weld width. } \\
\mathrm{d}:=7.88 \cdot \mathrm{in} & \text { Weld length. } \\
\mathrm{w}_{\mathrm{a}}:=\frac{1}{4} \cdot \mathrm{in} & \text { The actual weld size. } \\
\sigma_{\text {base }}:=46000 \cdot \frac{\mathrm{lb}}{\mathrm{in}^{2}} & \text { Yield stress of the base metal. } \\
\sigma_{\text {weld }}:=70000 \cdot \frac{\mathrm{lb}}{\mathrm{in}^{2}} & \text { Weld metal strength. }
\end{array}
$$

Connection Loads:

$$
\begin{array}{lll}
\mathrm{F}_{\mathrm{X}}:=\mathrm{F}_{\text {horz }} & \mathrm{F}_{\mathrm{y}}:=-\mathrm{F}_{\text {vert }} & \mathrm{F}_{\mathrm{z}}:=0 \cdot \mathrm{lb} \\
\mathrm{M}_{\mathrm{X}}:=0 \cdot \mathrm{in} \cdot \mathrm{lb} & \mathrm{M}_{\mathrm{y}}:=0 \cdot \mathrm{in} \cdot \mathrm{lb} & \mathrm{M}_{\mathbf{z}}:=\mathrm{M}_{\mathbf{z} \text { _weld }}
\end{array}
$$

The distance to the outer fiber in the $x$-direction.

The distance to the outer fiber in the $y$-direction. about the $x$-axis.

The linear section modulus about the $y$-axis.

The linear polar moment of inertia.
The linear section modulus

Linear Weld Stress:

$f_{w}:=\sqrt{\left(\frac{F_{z}}{A_{w}}+\frac{M_{x}}{S_{w x}}+\frac{M_{y}}{S_{w y}}\right)^{2}+\left(\frac{F_{x}}{A_{w}}+\frac{M_{z} C_{y}}{J_{w}}\right)^{2}+\left(\frac{F_{y}}{A_{w}}+\frac{M_{z} \cdot C_{x}}{J_{w}}\right)^{2}} \quad f_{w}=843.644 \cdot \frac{\mathrm{lb}}{\mathrm{in}}$

Required Fillet Weld Size:

$\mathrm{w}_{\mathrm{r}}:=\mathrm{if}\left[\frac{\mathrm{f}_{\mathrm{w}}}{0.4 \cdot \sigma_{\text {base }}} \leq \frac{\mathrm{f}_{\mathrm{w}}}{0.707 \cdot 0.3 \cdot \sigma_{\text {weld }}}, \frac{\mathrm{f}_{\mathrm{w}}}{0.4 \cdot \sigma_{\text {base }}}, \frac{\mathrm{f}_{\mathrm{w}}}{0.707 \cdot(0.3) \cdot \sigma_{\text {weld }}}\right] \quad \mathrm{w}_{\mathrm{r}}=0.046 \cdot \mathrm{in}$

0.707 is for shear through throat of fillet weld, 0.3 is allowable stress reduction factor for shear through throat of fillet weld and 0.4 is for shear on base metal. See AISC 1989, Table J2.5, Page 5-70.

The Margin of Safety:

MS : $: \frac{w_{a}}{w_{r}}-1$

$\mathrm{MS}=4.453$

OK 
HNF-4320

Rev. 0

1.0 OBJECTIVE The platforms used for core sampling are extremely narrow. This makes it very difficult to back a core sample truck up on to the platforms. To increase safety, fences were added to the platforms by ECN 639132. The fences come in $4 \mathrm{ft} \times 6$ in sections. Each fence is removable so as not to hinder core sampling operations. This set of calculations determines the adequacy of the fences.

\subsection{DESIGN INPUTS}

2.1 Design drawing $\mathrm{H}-2-85633$.

2.2 Engineering Change Notice, 639132.

\subsection{ASSUMPTIONS}

4.0 METHODS OF ANALYSIS (Hand Calculations)

\subsection{REFERENCES}

5.1 AISC, 1989, Manual of Steel Construction, 9th Edition, American Institute of Steel Construction, Chicago Illinois.

5.2 Blodgett, O W, 1991, Design of Welded Structures, Fourteenth Printing, The James F. Lincoln Arc Welding Foundation, Cieveland, Ohio.

6.0 FINDINGS AND CONCLUSIONS The fences and bumper are adequate to stop a core sample truck given that the truck is moving un-powered at $2 \mathrm{mph}$.

\subsection{CALCULATIONS}

7.1 Given the following dimensions determine the allowable lateral loading.
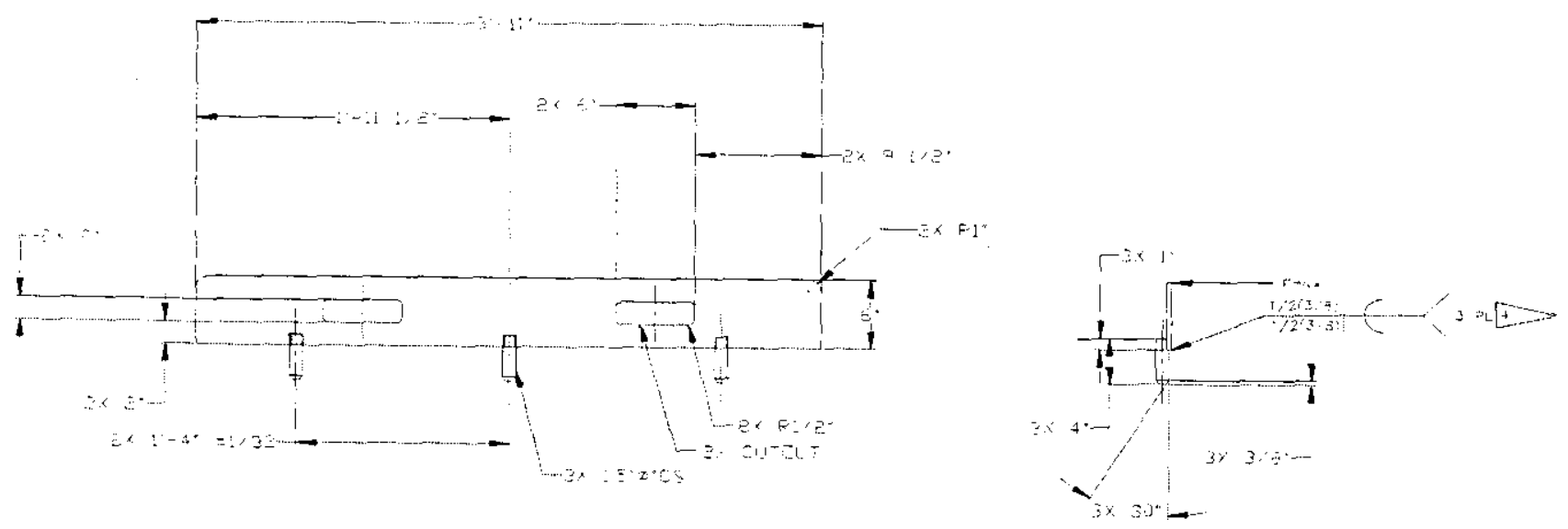


\section{The $5300 \mathrm{lb}$ load will result in either stopping of the core sample truck and/or enough noise and vibration for the driver and other operators to take notice and stop the core sample truck before the truck is driven off the side of the platform.}

$$
\begin{array}{ll}
r:=6 \cdot \text { in } & \text { Height of plate. } \\
M:=r \cdot F_{\max } & M=31800 \cdot \mathrm{in} \cdot \mathrm{lb}
\end{array}
$$

$$
M=31800 \text { ain } \cdot l b
$$

Maximum moment in the plate.

Check the adequacy of the pins.

$$
\begin{array}{ll}
\mathrm{d}:=1.5 \cdot \mathrm{in} & \text { Diameter of the pin. } \\
\mathrm{I}_{\text {pin }}:=\frac{\pi \cdot \mathrm{d}^{4}}{64} & \mathrm{I}_{\text {pin }}=0.249 \cdot \mathrm{in}^{4} \quad \text { Moment of inertia of the pin. } \\
\mathrm{A}_{\text {pin }}:=\frac{\pi}{4} \cdot \mathrm{d}^{2} & \mathrm{~A}_{\text {pin }}=1.767 \cdot \mathrm{in}^{2} \quad \text { Cross sectional area of the pin. } \\
\mathrm{M}_{\max }:=\frac{\mathrm{M}}{3} & 3 \text { pins will absorb the applied moment. } \\
\sigma_{b}:=\frac{M_{\max } \frac{\mathrm{d}}{2}}{T_{\text {pin }}} & \sigma_{b}=31991.322 \cdot \frac{\mathrm{lb}}{\mathrm{in}^{2}}
\end{array}
$$$$
\text { MS : }=\frac{\sigma_{y_{-} \text {a36 }}}{\sigma_{\mathrm{b}}}-1 \quad \mathrm{MS}=0.125
$$

Determine the maximum stress on the weld

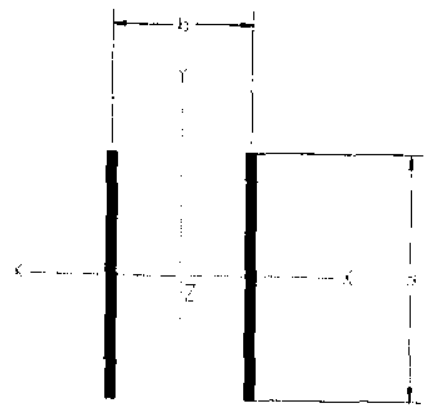

Weld Properties per Blodgett 1991:

$$
\mathrm{C}_{\mathrm{X}}:=2 \cdot \frac{\mathrm{b}}{2} \quad \mathrm{C}_{\mathrm{X}}=1.5 \text { oin }
$$

Weld Geometry.

$$
\begin{array}{ll}
\mathrm{b}:=1.5 \cdot \mathrm{in} & \text { The width of the weld. } \\
\mathrm{d}:=1 \cdot \mathrm{in} & \text { The length of the weld. } \\
\mathrm{w}_{\mathrm{a}}:=\frac{3}{8} \cdot \mathrm{in} & \text { The actual weld size. } \\
\sigma_{\text {base }}:=36000 \cdot \frac{\mathrm{lb}}{\mathrm{in}^{2}} & \text { Yield stress of the base metal. } \\
\sigma_{\text {weld }}:=70000 \cdot \frac{\mathrm{lb}}{\mathrm{in}^{2}} \quad \text { Weld metal strength. }
\end{array}
$$

Connection Loads:

$$
\begin{array}{lll}
F_{X}:=0 \cdot l b & F_{y}:=0 \cdot l b & F_{z}:=\frac{F_{\max }}{3} \\
M_{X}:=\frac{F_{\text {max }} \cdot 5.5 \cdot \text { in }}{3} & M_{y}:=0 \cdot \text { in } \cdot l b & M_{z}:=0 \cdot \text { in } \cdot l b
\end{array}
$$

OK Since this is an accident scenario the yield stress is used for the allowable stress. 
HNF-4320

Rev. 0
$C_{y}:=2 \cdot \frac{d}{2}$
$C_{y}=1 \cdot$ in
The distance to the outer fiber in the $y$-direction.
$A_{W}:=4 \cdot d$
$A_{w}=4 \cdot$ in
The linear area of the weld.
$S_{w x}:=2 \cdot \frac{d^{2}}{3}$
$S_{w x}=0.667 \mathrm{oin}^{2}$
The linear section modulus about the $\mathrm{x}$-axis.
$S_{\text {wy }}:=2 \cdot(b \cdot d)$
$S_{w y}=3 \cdot \mathrm{in}^{2}$
The linear section modulus about the $y$-axis.
$J_{w}:=2 \cdot \frac{d \cdot\left(3 \cdot b^{2}+d^{2}\right)}{6}$
$\mathrm{J}_{\mathrm{w}}=2.583 \cdot \mathrm{in}^{3}$
The linear polar moment of inertia.

Linear Weld Stress:

$f_{w}:=\sqrt{\left(\frac{F_{z}}{A_{w}}+\frac{M_{x}}{S_{w x}}+\frac{M_{y}}{S_{w y}}\right)^{2}+\left(\frac{F_{x}}{A_{w}}+\frac{M_{z} \cdot C}{J_{w}}\right)^{2}+\left(\frac{F y}{A_{w}}+\frac{M_{z} \cdot C_{x}}{J_{w}}\right)^{2}} \quad f_{w}=15016.667 \cdot \frac{\mathrm{lb}}{\text { in }}$

Required Weld Size:

$\mathrm{w}_{\mathrm{T}}:=\mathrm{if}\left(\frac{\mathrm{f}_{\mathrm{w}}}{\sigma_{\text {base }}} \leq \frac{\mathrm{f}_{\mathrm{w}}}{.707 \cdot \sigma_{\text {weld }}}, \frac{\mathrm{f}_{\mathrm{w}}}{\sigma_{\text {base }}}, \frac{\mathrm{f}_{\mathrm{w}}}{0.707 \cdot \sigma_{\text {weld }}}\right)$

$\mathrm{w}_{\mathrm{r}}=0.303$ in

The margin of safety:

MS : $=\frac{\mathrm{w}_{\mathrm{a}}}{\mathrm{w}_{\mathrm{r}}}-1 \quad$ MS $=0.236$

OK

Check bending of the fence.

$I_{\text {plate }}:=\frac{47 \cdot \mathrm{in} \cdot\left(\frac{3}{8} \cdot \mathrm{in}\right)^{3}}{12}$

$I_{\text {plate }}=0.207 \cdot \mathrm{in}^{4}$

Minimum moment of inertia of the plate.

$\mathrm{c}:=\frac{\frac{3}{8} \cdot \mathrm{in}}{2}$

Distance from centroid of the plate to the outer most fiber.

$\sigma_{b}:=\frac{M \cdot c}{\text { plate }}$

$\sigma_{b}=28868.085 \cdot \frac{\mathrm{lb}}{\mathrm{in}^{2}}$

Maximum bending stress in the plate.

MS : $=\frac{\sigma_{y_{-} \mathrm{a} 36}}{\sigma_{\mathrm{b}}}-1$

$\mathrm{MS}=0.247$

OK Since this is an accident scenario the yield stress is used for the allowable stress.

Determine the adequacy of the bumpers. The bumpers are constructed from $4 \times 4 \times 1 / 4$ in angle and are used to prevent the core sample truck from rolling off the end of the platform. The bumpers are attached to the platform using a minimum of two $\mathrm{A} 325$ bolts.

Use Kinetic Energy Theory

$\mathrm{V}:=2 \cdot \mathrm{mph}$

$\mathrm{h}:=\frac{\mathrm{V}^{2}}{2 \cdot \mathrm{g}}$
Maximum velocity of the core sample truck on the ramps or platform.

$\mathrm{h}=1.605$-in
This the height required to stop the core sample truck. Since the actual height is 4 in. OK 
HNF-4320

Rev. 0

APPENDIX B: Tank Farms Ramp and Platform Calculations

Page B-1 
Client: Characterization Equipment Subject: Analysis of Core Sampling Platform
WO/Job No.

Date: $4 / 7 / 99$

Checked: $-4-15-99$

Revised:

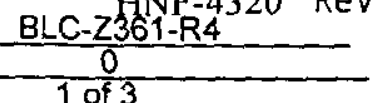

1.0 OBJECTIVE The calculations in BLC-Z361-R3 (Appendix A) determined the structural adequacy of the platform for use when core sampling tank 241-Z-361. The ramps and platforms must be combined with additional hardware to prevent the transmitting of moments to a foundation provided by Fluor Daniel Northwest. The calculations below determine the adequacy of the platform for use in $200 \mathrm{E}$ and $200 \mathrm{~W}$ Tank Farms without the use of the additional hardware required when sampling tank 241-Z-361. When the hardware is not used the ground shail absorb moments at the base of the platform through friction.

2.0 DESIGN INPUTS

2.1 Drawing: H-2-85633 Sheet 1, Rev. 0

3.0 ASSUMPTIONS None

4.0 METHODS OF ANALYSIS (Hand calculations completed in Mathcad ver. 8.0)

\subsection{REFERENCES} 5.1 AlSC, 1989, Manual of Steel Construction, $9^{\text {in }}$ Edition, American Institute of Steel Construction, Chicago,
Mlinois.

5.2 ASCE, 1996, Minimum Design Loads for Buildings and Other Structures, ANSI/ASCE 7-95, American Society of Civil Engineers, Reston, Virginia.

5.3 Coverdell, 1999, Design Loads and Center of Gravity For Core Sample Truck \#1, LMHC-9951531, Lockheed Martin Hanford Corp., Richland, Washington.

5.4 FDH, 1997, Engineering 20 Design and Evaluation, HNF-PRO-097, Fluor Daniel Hanford, inc., Richland,
Washington.

5.5 WHC, 1995 , Structural Evaluation for Core Sampling Trucks, RMCS Operations, 200 Area, WHC-SD-WM-DA-215, Westinghouse Hanford Company.

6.0 FINDINGS AND CONCLUSIONS The calculations below determined that given the shear connection between the W8 $\times 18$ beams and the TS $7 \times 4 \times 3 / 8$ columns, the friction force between the ground and the baseplate is adequate to resist the moment. The moment is caused by a $32000 \mathrm{lb}$ core sample truck plus the weight of 10 people plus $1000 \mathrm{lb}$ due to cask and cask stand for a total of $(35000 \mathrm{lb})$. 7.0 CALCULATIONS Determine if the maximum moment in the platform columns can be absorb by friction between the
baseplate and the soil.

7.1 Live Loads and core sample truck $\mathrm{Cg}$ location.

$$
\begin{aligned}
& P_{\text {truck }}:=32000 \cdot \mathrm{lb} \\
& P_{\text {human }}:=2000 \cdot \mathrm{lb} \\
& P_{\text {misc }}:=1000 \cdot \mathrm{lb} \\
& P_{\text {front }}:=11000 \cdot \mathrm{lb} \\
& P_{\text {rear }}:=21000 \cdot \mathrm{lb} \\
& \mathrm{Cg}_{x}:=156 \cdot \mathrm{in}
\end{aligned}
$$

Live load due to core sample truck, Coverdell, 1999.

Live load due to humans, Coverdell, 1999.

Live load due to casks and casks stand. NOTE: In service, this equipment will not be placed directly on a single platform but will be supported between two platforms.

Weight of core sample truck front axle as recorded by the state of Washington.

Weight of core sample truck rear axle as recorded by the state of Washington.

Horizontal distance to CG of sample truck. Measured from center of front axle, see picture on the following page.

Page B-2 
7.2 Determine the maximum wind force on the core sample truck given that the truck is performance category 1 (PC1).

$\mathrm{K}_{\mathrm{Z}}:=.85$

$\mathrm{K}_{\mathrm{zt}}:=1$

$I: \approx 1.0$

$v_{85}:=85$

$\mathrm{q}_{z_{-} 85}:=.00256 \cdot \mathrm{K}_{z^{\prime}} \cdot \mathrm{K}_{z \mathrm{t}^{\prime}} \cdot \mathrm{V}_{85}{ }^{2} \cdot \frac{\mathrm{lb}}{\mathrm{ft}^{2}}$

$\mathrm{G}:=.85$

$\mathrm{C}_{\mathrm{f}}:=2$ (conservative)

$A_{f}:=29133 \cdot \mathrm{in}^{2}$

$P_{w_{-} 85}:=q_{z_{-}} 85 \cdot G \cdot C_{f} A_{f}$
Exposure category C, table 6-3 of ASCE 1996

Per paragraph 6.5.5 of ASCE 1996.

Importance factor per FDH 1997.

Wind velocity per FDH 1997.

$q_{z_{-} 85}=15.722 \cdot \frac{\mathrm{lb}}{\mathrm{ft}^{2}} \quad$ Velocity pressure.

Gust effect factors determined from paragraph 6.6.1 of ASCE 1996.

From Table 6-8 of ASCE 1996 given a height of $10 \mathrm{ft}$.

Surface area of core sample truck based on AutoCAD surface area calculations..

$P_{W \_85}=5407 \mathrm{lb} \quad$ Wind force on core sample truck.

7.3 Determine the increased reaction force on the rear axle due to a $85 \mathrm{mph}$ wind loading.
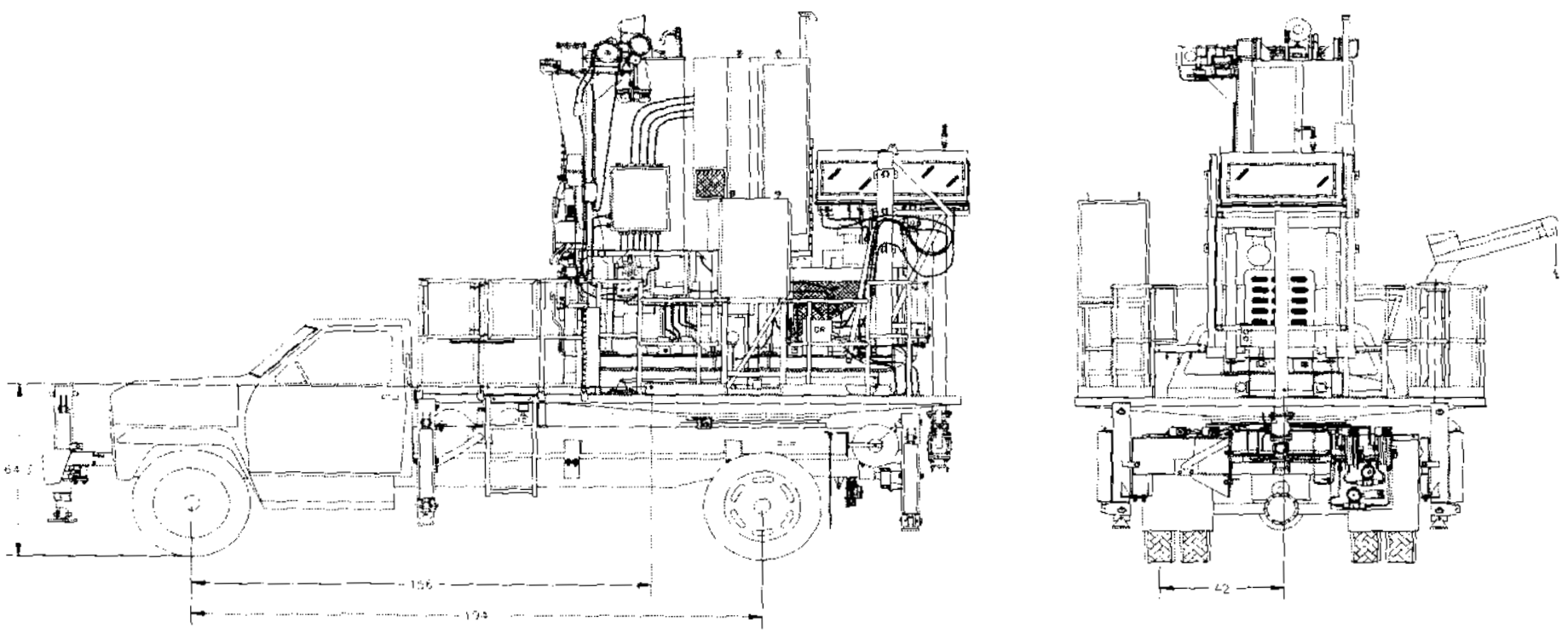

$\mathrm{e}_{1}:=84 \cdot$ in

$\mathrm{e}_{2}:=194$ in

$\tau_{\text {rear85 }}:=\frac{\mathrm{Cg}_{\mathrm{X}} \cdot \mathrm{P}_{\mathrm{w}_{-} 85}}{\mathrm{e}_{2}}$

$\tau_{w_{-} 85}:=\frac{\mathrm{Cg}_{y} \cdot \mathrm{r} \text { rear85 }}{\mathrm{e}_{1}}$
Distance between tire center lines on rear axle.

Distance between centerlines of front and rear tires.

$r_{\text {rear85 }}=4348 \mathrm{lb}$

$85 \mathrm{mph}$ wind force on rear axle.

$r_{w_{-} 85}=3328 \mathrm{lb}$
Additional force on one side of rear axle due to $85 \mathrm{mph}$ wind loading. 
HNF-4320, Rev. 0

7.5 Calculate the maximum horizontal and vertical loadings for load cases one and two.

Load Case

$$
\begin{array}{lll}
P_{\text {vert }}:=\frac{P_{\text {rear }}}{2}+\frac{P_{\text {misc }}}{2}+r_{w_{-} 85} & P_{\text {vert }}=14328 \mathrm{lb} & \begin{array}{l}
\text { Vertical Loading: 1/2 rear axle load }+1 / 2 \text { cask load } \\
+85 \mathrm{mph} \text { wind load. }
\end{array} \\
P_{\text {horz }}:=P_{w_{\_} 85} & P_{\text {horz }}=5407 \mathrm{olb} & \text { Horizontal Loading due to wind. }
\end{array}
$$

7.6 Calculate the required horizontal force at the base to resist the moment developed by $P_{\text {vert }}$ located at the midspan of the platform and the wind force. Per AISC 1989 the connection between the beams and the columns as a shear
connection.

$\begin{array}{ll}\mathrm{L}_{\text {column }}:=20.5 \cdot \text { in } & \text { From H-2-85633. } \\ \text { Depth }:=8.125 \text { in } & \text { Depth of W8 } \times 18 .\end{array}$

$\mathrm{N}:=.4$

The coefficient of friction between steel and soil.

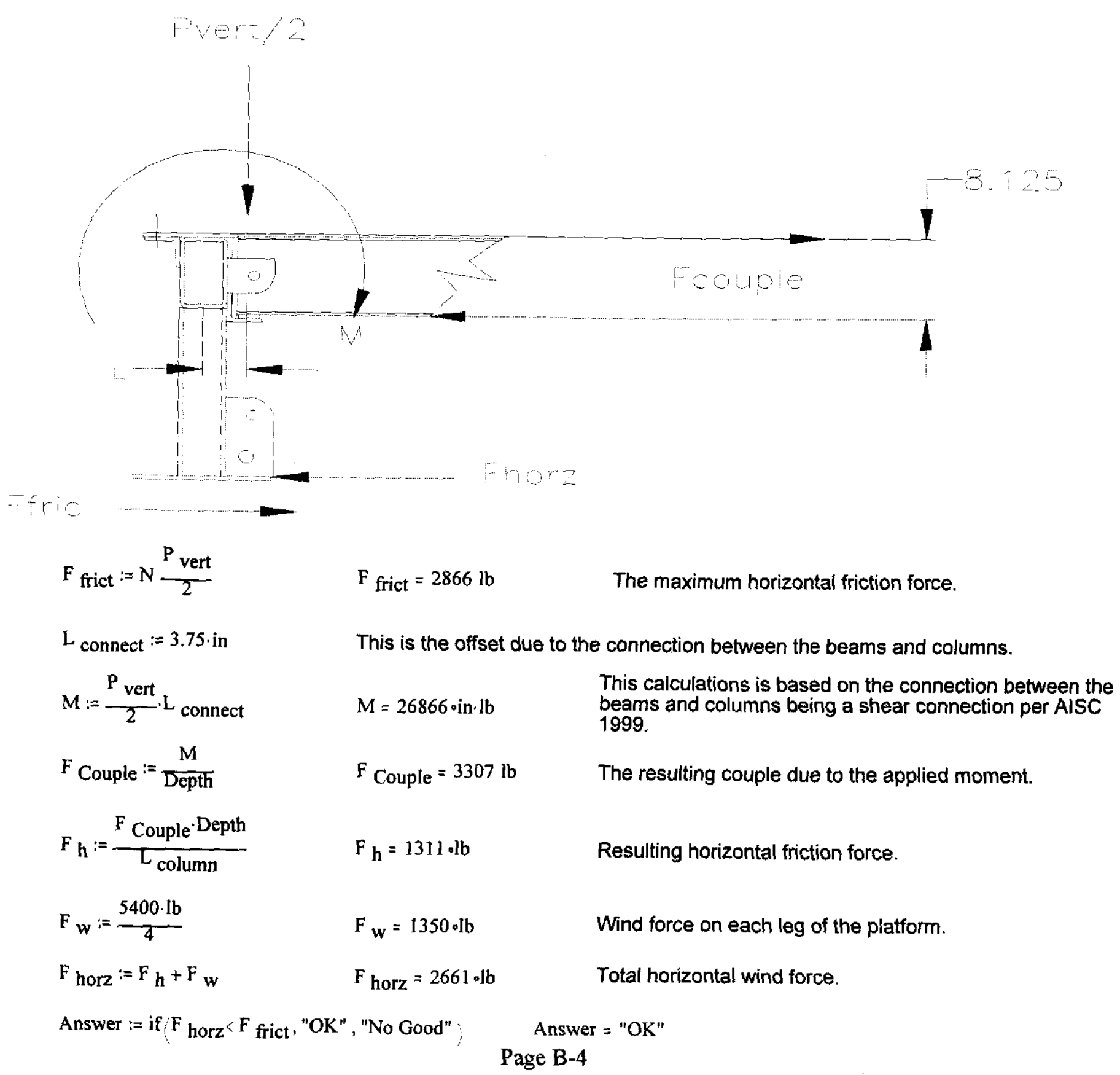


HNF-4320, Rev. 0

APPENDIX C: Engineering Change Notice 651132

Page C-1 
HNF-4320, Rev, 0

\section{ENGINEERING CHANGE NOTICE}

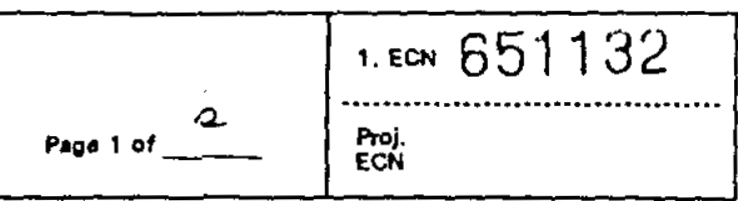

\begin{tabular}{|c|c|c|c|c|}
\hline $\begin{array}{l}\text { 2. ECN Category } \\
\text { (mark one) } \\
\text { Supplemental }\end{array}$ & ] & $\begin{array}{l}\text { 3. Originator's Name, Organization, MSIN, and } \\
\text { Telephone No. } \\
\text { B.L. Coverdell, 08E00, S7-12, 373-0598 }\end{array}$ & $\begin{array}{l}\text { 4. USQ Required? } \\
{[X] \text { Yes [] No }}\end{array}$ & $\begin{array}{l}\text { 5. Date } \\
\text { April 28, } 1999\end{array}$ \\
\hline $\begin{array}{l}\text { Direct Revision } \\
\text { Change ECN } \\
\text { Temporary }\end{array}$ & [X] & $\begin{array}{l}\text { 6. Project Title/No./Work Order No. } \\
\text { Characterization Project / CACN } 102250\end{array}$ & 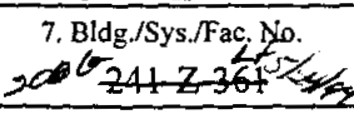 & $\begin{array}{l}\text { 8. Approval Designator } \\
\text { SQ }\end{array}$ \\
\hline $\begin{array}{l}\text { Standby } \\
\text { Supersedure } \\
\text { Cance/Void }\end{array}$ & $\underset{[X]}{0}$ & $\begin{array}{l}\text { 9. Document Numbers Changed by this ECN } \\
\text { (includes sheet no. and rev.) } \\
\text { H-2-85633, SH 1, REV 0 }\end{array}$ & 10. Related ECN No(s) & 11. Related PO No. \\
\hline
\end{tabular}

12a. Modification Work
ofe $5 / 24 / 99$
[X]Yes (fill out Blk. 12b)
[] No (NA B1ks. 12b,
$12 \mathrm{c}, 12 \mathrm{~d}$ )

13a. Description of Change

RELATED ECNS:

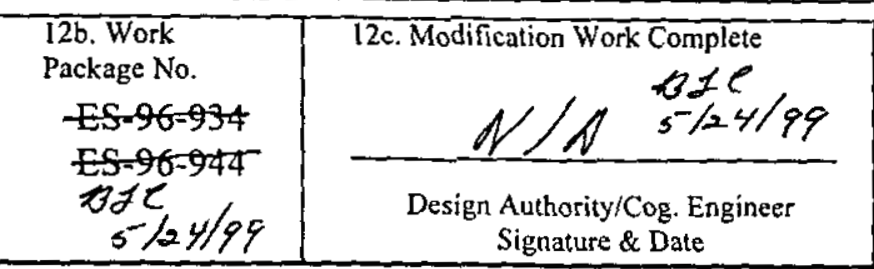

13b. Design Baseline Document? [X] Yes [] No 12d. Restored to Original Condition (Temp. or Standby ECN only)

\begin{tabular}{c} 
N/A \\
$\begin{array}{c}\text { Design Authority/Cog. Engineer } \\
\text { Signature \& Date }\end{array}$ \\
\hline
\end{tabular}

THIS ECN CANCELS ECN 639132. THIS ECN IS NOT WORK COMPLETE.

THIS ECN INCORPORATES ECNS 632442 AND 636563. BOTH THESE ECNS ARE WORK COMPLETE.

THIS ECN ADDS STRUCTURAL MEMBERS TO THE RAMP AND PLATFORM ASSEMBLIES FOR USE WITH CORE SAMPLING TRUCKS (H-2-690000, H-2-140300 AND H-2-91701). THESE MODIFICATIONS ARE REQUIRED FOR CORE SAMPLING OF TANK 241-Z,-361. THE MODIFICATIONS INCLUDE THE ADDITION OF CROSS BRACING, TIE RODS, FENCING AND WHEEL STOPS. THE CROSS BRACING CONNECTS THE TOP OF EACH LEG TO THE BOTTOM OF THE OPPOSING LEG ON BOTH THE LATERAL AND LONGITUDINAL SIDES. THE TIE RODS CONNECT THE BOTTOM OF BOTH LEGS ON THE LONGITUDINAL SIDE. THE FENCING AND WHEEL STOPS PREVENT A CORE SAMPLE TRUCK FROM ROLLING OFF THE PLATFORM.

Add sheets 2 -4 tozC $5-124 / 99$.

14a. Justification (mark one)

$\begin{array}{lllllll}\text { Criteria Change } & {[\mathrm{X}]} & \text { Design Improvement } & {[]} & \text { Environmental } & {[]} & \text { Facility Deactivation [] } \\ \text { As-Found } & {[]} & \text { Facilitate Const } & {[]} & \text { Const. Error/Omission } & {[]} & \text { Design Error/Omission [] }\end{array}$

14b. Justification Details

- MODIFICATIONS ARE REQUIRED TO SATISFY REQUIREMENTS ASSOCIATED WITH CORE SAMPLING OF TANK 241 -Z-361 AS INDICATED IN BLOCK 21.

- THIS DESIGN WILL NOT RESULT IN AN EXPOSURE CHANGE >1 PERSON-REM (WHOLE BODY) OR $>10$ PERSON-REM (EXTREMITIES) FOR THE INSTALLATION, MAINTENANCE AND OPERATION OF THE LIFE OF THE MODIFICATION.

- THIS ECN IS COVERED BY USQ TF-99-299.

- DESIGN VERIFICATION PERFORMED BY INFORMAL REVIEW PER HNF-IP-0842, VOL IV, SECTION 4.24.

15. Distribution (inciude name, MSIN, and no. of copies)

$\begin{array}{llllll}\text { M. E. Beaver } & \$ 7-12 & 1 \text { COPY } & \text { K. D. Hein } & \$ 7-12 & 1 \text { COPY } \\ \text { R. M. Boger } & \$ 7-12 & 1 \text { COPY } & \text { J. Lipnicki } & 57-12 & 1 \text { COPY } \\ \text { B. L. Coverdell } & \$ 7-12 & 1 \text { COPY } & \text { E. E. Salinas } & 57-12 & 1 \text { COPY } \\ \text { R. N. Dale } & \$ 7-12 & 1 \text { COPY } & \text { J. L. Smalley } & \$ 7-12 & 1 \text { COPY } \\ \text { R. E. Falon } & \text { S7-04 } & \text { 1 COPY } & \text { G. W. Wilson } & \$ 7-12 & 1 \text { COPY } \\ \text { T. R. Farris } & \text { S7-12 } & \text { 1 COPY } & & & \end{array}$

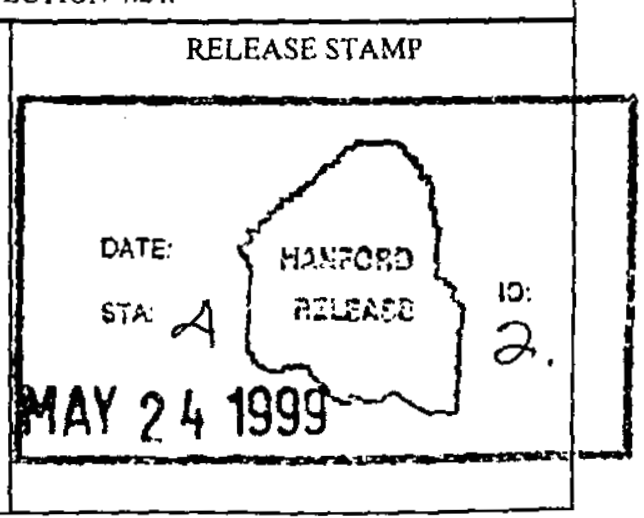

A-7900-013-2 (05/96) GEF095 


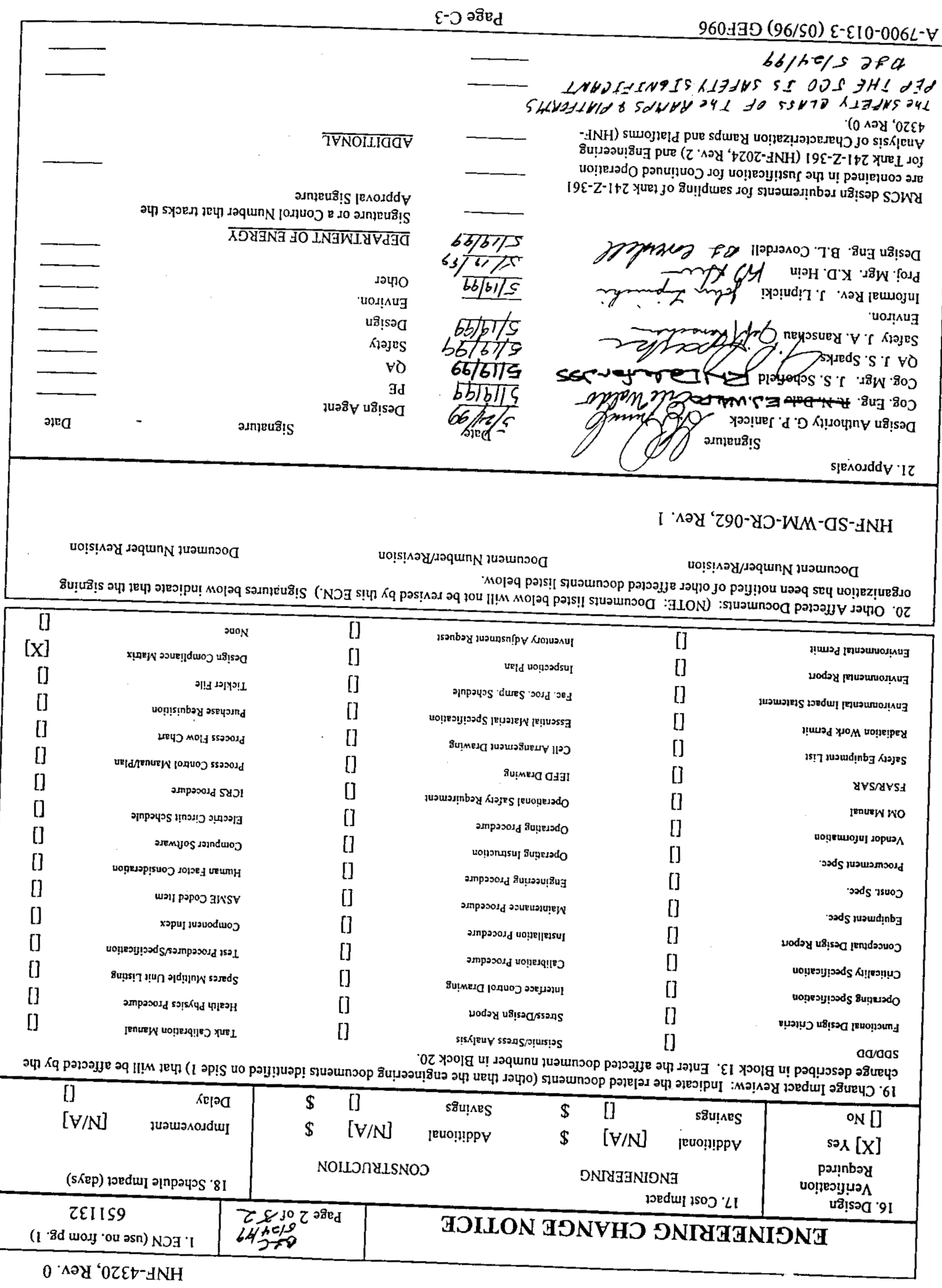

